\title{
Cell Migration along the Lateral Cortical Stream to the Developing Basal Telencephalic Limbic System
}

\author{
Rosalind S. E. Carney, ${ }^{1,2}$ Teresa B. Alfonso, ${ }^{1}$ Daniela Cohen, ${ }^{3}$ Haining Dai, ${ }^{1}$ Susana Nery, ${ }^{3}$ Bogdan Stoica, ${ }^{1}$ \\ Jonathan Slotkin, ${ }^{1}$ Barbara S. Bregman, ${ }^{1}$ Gord Fishell, ${ }^{3}$ and Joshua G. Corbin ${ }^{1,2}$ \\ ${ }^{1}$ Department of Neuroscience, Georgetown University Medical Center, Washington, DC 20057, ${ }^{2}$ Center for Neuroscience Research, Children's Research \\ Institute, Children's National Medical Center, Washington, DC 20010, and ${ }^{3}$ Developmental Genetics Program and the Department of Cell Biology, Skirball \\ Institute of BioMolecular Medicine, New York University Medical Center, New York, New York 10016
}

During embryogenesis, the lateral cortical stream (LCS) emerges from the corticostriatal border (CSB), the boundary between the developing cerebral cortex and striatum. The LCS is comprised of a mix of pallial- and subpallial-derived neural progenitor cells that migrate to the developing structures of the basal telencephalon, most notably the piriform cortex and amygdala. Using a combination of in vitro and in vivo approaches, we analyzed the timing, composition, migratory modes, origin, and requirement of the homeodomaincontaining transcription factor Gsh2 (genomic screened homeobox 2) in the development of this prominent migratory stream. We reveal that Pax6 (paired box gene 6)-positive pallial-derived and Dlx2 (distal-less homeobox 2)-positive subpallial-derived subpopulations of LCS cells are generated in distinct temporal windows during embryogenesis. Furthermore, our data indicate the CSB border not only is comprised of separate populations of pallial- and subpallial-derived progenitors that contribute to the LCS but also a subpopulation of cells coexpressing Pax6 and Dlx2. Moreover, despite migrating along a route outlined by a cascade of radial glia, the Dlx2-positive population appears to migrate primarily in an apparent chain-like manner, with LCS migratory cells being generated locally at the CSB with little contribution from other subpallial structures such as the medial, lateral, or caudal ganglionic eminences. We further demonstrate that the generation of the LCS is dependent on the homeodomain-containing gene $G s h 2$, revealing a novel requirement for $G s h 2$ in telencephalic development.

Key words: amygdala; development; pallium; radial glia; specification; subpallium

\section{Introduction}

The basal limbic system of the mammalian telencephalon is comprised of a number of complex structures that includes the piriform cortex, amygdala, and nucleus accumbens. These regions, together with other forebrain limbic structures (prefrontal cortex, cingulate cortex, hippocampus, and hypothalamus) form a circuit that regulates a number of essential behaviors, including specific aspects of memory and emotion and the regulation of motivational stages involved with drives. Currently, the level of understanding of basal telencephalic limbic system development does not rival that of the cerebral cortex. In the cerebral cortex,

\footnotetext{
Received Jan. 31, 2006; revised Sept. 22, 2006; accepted Sept. 22, 2006.

This work was supported by a grant from the National Alliance for Autism Research, MRDDRC award from the Children's Research Institute, Washington, DC, National Institutes of Health Grants DA020140 (J.C.), NS 27054 (H.D. and B.S.B.), NS032993 (G.F.), MH071679 (G.F.), and MH068469 (G.F.), and National Institute of Child Health and Human Development Grant T32HD 007459 (J.S. and B.S.B.). We thank Dr. Arturo Alvarez-Buylla for his input on early stages of this work, Dr. Molly Huntsman for sharing of equipment, Dr. Tarik Haydar and Randi Goodnight for technical assistance, and members of the Corbin, Fishell, and Haydar labs for their helpful discussions and insight.

Correspondence should be addressed to Dr. Joshua Corbin, Center for Neuroscience Research, Children's Research Institute, Suite 5347, Children's National Medical Center, 111 Michigan Avenue NW, Washington, DC 20010. E-mail: jcorbin@cnmcresearch.org.

S. Nery's present addresses: London School of Hygiene and Tropical Medicine, Department of Infectious and Tropical Diseases, Unit of Pathogen Molecular Biology, Keppel Street, London WC1E 7HT, UK.

J. Slotkin's present address: Department of Neurosurgery, The Brigham and Women's Hospital, Children's Hospital Boston, Harvard Medical School, Boston, MA 02115.

DOI:10.1523/JNEUROSCI.3092-06.2006

Copyright $\odot 2006$ Society for Neuroscience $\quad$ 0270-6474/06/2611562-13\$15.00/0
}

regional neuronal cell diversity is established by the convergence of migratory progenitor cells from both pallial (dorsal telencephalic) and subpallial (ventral telencephalic) compartments. Future excitatory neurons are locally generated in the pallial neuroepithelium and migrate radially to their laminar destination (Rakic, 1974). In contrast, the majority of inhibitory neurons is derived from the subpallial progenitor zones, most notably the medial (MGE) and caudal (CGE) ganglionic eminences, and migrate tangentially to the developing cerebral cortex (for review, see Corbin et al., 2001; Marin and Rubenstein, 2001). Importantly, these separate subpallial progenitor zones give rise to inhibitory neurons with distinct spatial, neurochemical, morphological, and electrophysiological characteristics (Nery et al., 2002; Xu et al., 2004; Butt et al., 2005).

In contrast to the vast waves of dorsally directed migrating neural precursor cells from the subpallium, cells of the lateral cortical stream (LCS) migrate in the opposite direction from dorsal to more ventral telencephalic regions. During embryogenesis, cells of the LCS emerge from the "molecular" corticostriatal border (CSB), the region of the dorsal LGE (dLGE) in which pallial gene expression [e.g., Pax6 (paired box gene 6) and Ngn2 (neurogenin homolog 2)] abuts subpallial gene expression [e.g., Gsh2 (genomic screened homeobox 2) and Dlx1/2 (distal-less homeobox 2) (for review, see Corbin et al., 2001; Molnár and Butler, 2002)]. This "molecular" CSB (herein referred to as CSB) is po- 
sitioned just ventral to the corticostriatal sulcus and also is the site of expression of a variety of specific intrinsic [e.g., Dbx1 (developing brain homeobox 1), Er81 (Ets transcription factor ER81), Sp8 (a member of the Sp1 zinc finger transcription factor gene family), and Tsh1 (Teashirt 1)] and extrinsic [e.g., Sfrp2 (secreted frizzled-related protein 2), Tgf- $\alpha$, and Fgf7] factors (Lu et al., 1996; Kim et al., 2001; Assimacopoulos et al., 2003; Stenman et al., 2003a; Caubit et al., 2005; Waclaw et al., 2006). Furthermore, gene expression studies have indicated that the LCS consists of at least two progenitor populations that arise from both the pallial and subpallial compartments (Stoykova et al., 1996; Puelles et al., 2000; Toresson et al., 2000; Yun et al., 2001; Medina et al., 2004; Tole et al., 2005).

The first evidence that the CSB region contributes cells to the basal telencephalic limbic system came from early birthdating studies (Hicks and D'Amato, 1968; Bayer and Altman, 1991) (for review, see Molnár and Butler, 2002), with more recent studies using DiI (de Carlos et al., 1996) or labeled retroviruses (Suzuki and Goldman, 2003), to reveal complex dynamic patterns of migration along the LCS to the basal telencephalon. A number of genetic studies are also consistent with the LCS being a significant source of cells for the subregions of the basal telencephalic limbic system, including the amygdala and piriform cortices (Stoykova et al., 2000; Toresson et al., 2000; Yun et al., 2001). Interestingly, it appears the CSB (dLGE) may also be the embryonic source of progenitor cells that migrate along the rostral migratory stream (RMS) to give rise to olfactory bulb interneurons, as well as to precursor cells in the postnatal subventricular zone (SVZ) (Marshall and Goldman, 2002; Stenman et al., 2003a, Caubit et al., 2005; Waclaw et al., 2006).

Despite the evidence that the LCS contributes neural progenitor cells to the basal telencephalic limbic system, little is currently known regarding the embryonic development of this complex migratory stream. In this study, we examined a number of important characteristics of the LCS, including the timing of the generation of migratory cells, cellular composition, pathway and mode of migration, embryonic origin, and the genetic requirement of the homeodomain-containing gene Gsh2 in its development.

\section{Materials and Methods}

Animal use. Swiss Webster (Taconic Farms, Albany, NY) and CD1 (Harlan Sprague Dawley, Indianapolis, IN) mice used in these studies were maintained according to protocols approved by New York University School of Medicine and Georgetown University Medical Center. For staging of the embryos, midday of the day of vaginal plug detection was considered as embryonic day 0.5 (E0.5). For postnatal animals, the day of birth was considered as postnatal day 0 . The generation and genotyping of $G s h 2^{-/-} ; D l \times 2^{+/ t a u L a c Z}$ and $N k \times 2.1^{-1-} ; D l \times 2^{+/ t a u L a c Z}$ embryos were performed as described previously (Corbin et al., 2000; Nery et al., 2003). For Gsh2 and Nkx2.1 [NK2 transcription factor-related; also known as TTF1 (thyroid transcription factor 1)] genotypes, both littermate heterozygote and wild-type mice were used as controls. For cell and tissue transplantation experiments, transgenic embryos constitutively expressing either placental alkaline phosphatase (PLAP) (DePrimo et al., 1996) or green fluorescent protein (GFP) (Okabe et al., 1997) were used as donors as described previously (Nery et al., 2002; Butt et al., 2005). Fur-

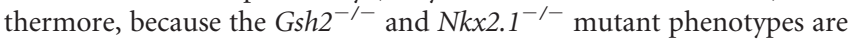
fully penetrant, in all cases the number of animals in which the phenotype was observed is equal to the $n$ of animals examined.

Tissue preparation and histology. For immunofluorescence, in situ hybridization, and 5-bromo-4-chloro-3-indolyl- $\beta$-D-galactopyranoside (X-gal) staining, at E17.5 and younger, heads of embryos were postfixed in $4 \%$ paraformaldehyde (PFA) in $0.1 \mathrm{M} \mathrm{PBS}, \mathrm{pH} 7.4$, at $4^{\circ} \mathrm{C}$ for $4-6 \mathrm{~h}$. For embryos older than E17.5 and postnatal mice, fixation was achieved by transcardial perfusion and postfixation in 4\% PFA. All brains were cryoprotected by sucrose immersion before embedding in HistoPrep (Fisher Scientific, Pittsburgh, PA) and frozen. Serial coronal sections of embedded tissue were cut (20-40 $\mu \mathrm{m}$ thickness, depending on the age) using a cryostat. X-gal staining on frozen sections was preformed as described previously (Corbin et al., 2000).

Immunohistochemistry. Cryocut mounted sections were air dried and underwent rinses in PBS before blocking of nonspecific binding sites using $10 \%$ normal serum diluted in PBS with $0.02 \%$ Triton X-100 to aid permeabilization. Primary antibody mixtures were made up in PBS $(0.2 \%$ Triton X-100 with $1 \%$ normal serum) and incubated overnight at $4^{\circ} \mathrm{C}$. The primary antibodies used were as follows: mouse-anti RC2 (1:5; Developmental Hybridoma Studies Bank, University of Iowa, Iowa City, IA), mouse anti-neuronal class III $\beta$-tubulin (TUJ1) (1:2000; Covance Research Products, Berkeley, CA), goat anti- $\beta$-galactosidase (1:200; Biogen, Cambridge, MA), rat anti-5-bromo-2'-deoxyuridine (BrdU) (1:250; Serotec, Oxford, UK), rabbit anti-brain lipid binding protein (BLBP) (1:1500; gift from Dr. Todd Anthony, Rockefeller University, New York, NY), rabbit anti-Pax6 (1:1000; Covance Research Products), rabbit anti-Ki67 (1:500; Novocastra, Newcastle, UK), and rabbit-anticalbindin (1:400; Calbiochem, La Jolla, CA). For primary antibody detection, secondary antibodies against goat, mouse, rat, and rabbit IgG or mouse IgM (RC2) were used (cyanine 3 and 5, 1:200; FITC, 1:50; all from Jackson ImmunoResearch, West Grove, PA) and diluted as for the primary antibodies. Nuclear counterstaining was performed by incubation in To-Pro-3 iodide (1:100; Invitrogen, Carlsbad, CA) for $10 \mathrm{~min}$ at room temperature. Final rinses in PBS were performed before coverslipping.

BrdU labeling. To label S-phase cells, an E15.5 Dlx $2^{+/ t a u L a c Z}$ pregnant dam was administered BrdU (Sigma, St. Louis, MO) by intraperitoneal injection (dissolved in PBS) at a dose of $40 \mathrm{mg} / \mathrm{kg}$. To achieve short-term labeling, the dam was killed after $2 \mathrm{~h}$, and the embryos were harvested, fixed in PFA, and frozen embedded as described above. Cryostat sections were pretreated with $2 \mathrm{~N} \mathrm{HCl}$ for $45 \mathrm{~min}$ at $37^{\circ} \mathrm{C}$ for DNA denaturation, before standard immunohistochemical procedures.

Electron microscopy. Whole-mount E15.5 Dlx $2^{+ \text {tauLacZ }}$ brains were fixed with $1 \% \mathrm{PFA} / 2 \%$ glutaraldehyde in $0.1 \mathrm{~m}$ phosphate buffer $(\mathrm{PB})$ for $2 \mathrm{~h}$, rinsed four times ( 5 min each) in PBS, and X-gal stained, and the CSB region from LacZ-positive $\left(\mathrm{LacZ}^{+}\right)$brains was dissected using Lumsden BioScissors (Bio-Rad, Hercules, CA). This was followed by postfixation with $1 \%$ osmium tetroxide in $\mathrm{PB}$ for $1 \mathrm{~h}$. After additional rinsing (four times for 5 min each), the specimens were stained with $2 \%$ uranyl acetate for $20 \mathrm{~min}$ in the dark, rinsed (four times for 5 min each with $\mathrm{dH}_{2} \mathrm{O}$ ), and dehydrated through a series of graded ethyl alcohols (50, 70, 95, 95, 100, and $100 \%$ ) for 10 min each. The specimens were transferred into $100 \%$ propylene oxide (two times for $15 \mathrm{~min}$ each) and finally into a 50:50 mixture of propylene oxide and the embedding resin (Embed 812; Electron Microscopy Sciences, Fort Washington, PA) overnight. Specimens were then transferred to fresh $100 \%$ embedding media for $6 \mathrm{~h}$, changed into fresh $100 \%$ embedding media, and kept in a $62^{\circ} \mathrm{C}$ oven for $12-18 \mathrm{~h}$. The blocks were cut at a thickness of $1 \mu \mathrm{m}$ or $85 \mathrm{~nm}$ for light microscopic or electron microscopic (H-7600; Hitachi, Pleasanton, CA) analysis, respectively. Slot copper grids $(2 \times 1)$ coated with Formvar/carbon film were used for electron microscopy.

Matrigel experiments. E13.5 embryos from $G s h 2^{+/-} ; D l x 2^{+/ t a u L a c Z} \times$ $G s h 2^{+/-}$crosses were harvested by cesarean section of dams and rapidly placed in chilled L-15 medium (Invitrogen). Heads were dissected, embryo bodies were immediately processed for X-gal staining, and only brains from $\mathrm{LacZ}^{+}$embryos were used. Embryos were genotyped as described previously (Corbin et al., 2000). Coronal explants containing the CSB region were dissected along the rostrocaudal axis of the brain by hand using Lumsden BioScissors. The ventralmost two-thirds of the LGE was cut away to permit cell migration on the Matrigel surface along the putative LCS. The explants were cultured in Neurobasal medium (Invitrogen), supplemented with penicillin/streptomycin (1:100; Invitrogen) B27 supplement (1:50; Invitrogen) and glutamine (1:100; Invitrogen) for 3-4 d in vitro (DIV). The explants were fixed in 4\% PFA for 20 min, rinsed briefly in PBS, and then processed for X-gal staining. Whether Dlx $2^{+}$cell migration occurred along the putative LCS and RMS 
in mutant and control explants was assayed blindly by two independent observers.

In utero transplantation. Cells dissected from different progenitor zones from E15.5 $\mathrm{GFP}^{+}$ (CSB) or E13.5 $\mathrm{PLAP}^{+}$(LGE, MGE, and CGE) transgenic mice were homotypically transplanted into age-matched wild-type embryos, guided by ultrasound biomicroscopy (UBM) microscopy (E-Technologies, Bettendorf, IA) as described previously (Liu et al., 1998; Wichterle et al., 2001; Nery et al., 2002; Butt et al., 2005). The transplanted embryos were harvested 2-4 $\mathrm{d}$ after transplantation by fixation of heads (younger than E17.5) or transcardial perfusion. Postfixed brains were cryoprotected by sucrose immersion before embedding in HistoPrep and sectioned coronally at $50 \mu \mathrm{m}$ on a cryostat. Sections from $\mathrm{GFP}^{+}$transplanted brains were rinsed in PBS, coverslipped, and analyzed using epifluorescence microscopy. Sections from PLAP ${ }^{+}$transplanted brains were incubated in PBS at $65^{\circ} \mathrm{C}$ for $30 \mathrm{~min}$, rinsed in alkaline phosphatase buffer (in mm: 100 Tris, $\mathrm{pH} 9.5,50 \mathrm{MgCl}_{2}$, and $10 \mathrm{NaCl}$ ), and stained for alkaline phosphatase with nitroblue-tetrazolium-chloride/5-bromo-4-chlor-indolyl-phosphate (Roche, Indianapolis, IN).

Organotypic cultures. Time-mated wild-type CD1 dams at E13.5 gestation were killed, and harvested embryos were placed in chilled sterile HBSS (Cellgro, Herndon, VA). The brains were dissected in ice-cold HBSS and embedded in low-melting agarose (3\% in HBSS), and 300$\mu \mathrm{m}$-thick coronal sections were cut using a Vibratome (VT1000S; Leica, Nussloch, Germany). The sections were transferred onto black-gridded $0.45 \mu \mathrm{m}, 13 \mathrm{~mm}$ nitrocellulose membranes (Millipore, Bedford, MA) in media containing MEM supplemented with 10\% fetal bovine serum, L-glutamine, and penicillin/streptomycin, and placed in an incubator $\left(37^{\circ} \mathrm{C}, 5 \% \mathrm{CO}_{2}\right)$ for $1-2 \mathrm{~h}$ for recovery. Explants from the $\mathrm{CSB}$, LGE, MGE, and CGE of $\mathrm{GFP}^{+}$age-matched embryos were then grafted homotypically onto the wild-type cultures. After grafting $\mathrm{GFP}^{+}$ explants, the cultures were transferred into Neurobasal media containing B27 supplement and penicillin/streptomycin and were further incubated for 2 DIV. The cultures were fixed in 4\% PFA for $30 \mathrm{~min}$, mounted on cavity slides, and coverslipped for analysis. Process orientation was quantified by counting the number of cells in which the leading process could be clearly identified. Based on the orientation of the leading process, migratory direction was assigned to one of four bins each representing a quadrant of a circle.

Data analysis. Digital photographs of X-gal-stained brains were obtained using bright-field microscopy (Axioplan 2; Zeiss, Oberkochen, Germany). For fluorescence, digital photographs were obtained from epifluorescence microscopy (Axiophot; Zeiss) and selected for additional analysis performed by confocal microscopy (LSM510 META; Zeiss). For some panels, each fluorophore was scanned sequentially, and $Z$-stacks of the images obtained were collapsed into a single projection image using the LSM510 software. These images were reconstructed, and the images obtained with different filters were merged using Adobe Photoshop 6.0 software (Adobe Systems, San Jose, CA). Adjustments to color and/or contrast were applied across each image as a whole and equally to control and mutant brains. For anatomical descriptions, the Paxinos and Franklin (2000) adult mouse brain atlas was used. To determine the extent of colocalization of immunofluorescent markers, the following criteria were applied: (1) in all cases, we also stained the sections with To-Pro-3 iodide as a nuclear marker to visualize individual cell nuclei, and colocalized cells were only scored as double labeled if an immunopositive cell body was clearly surrounded by an immunopositive nucleus that also was
To-Pro-3 iodide positive; (2) images used for quantification were individual optical confocal sections as opposed to a collapsed projection image; and (3) in all cases, quantification was undertaken by two independent observers.

\section{Results}

Time course of $\mathrm{Pax}^{+}{ }^{+}$and Dlx ${ }^{+}$cell migration to the basal telencephalon

Previous studies have revealed the presence of putative LCSderived $\mathrm{Pax}^{+}$cells in the region of the developing basolateral telencephalon from as early as E12.5 (Tomioka et al., 2000; Toresson et al., 2000; Yun et al., 2001; Hirata et al., 2002; Stenman et al., 2003b). In contrast, little is known regarding the timing of migration of the $\mathrm{Dlx} 2{ }^{+}$population along this route. Therefore, to directly compare the time course of the development of these two migratory populations, $\mathrm{Pax}^{+}$cells were visualized by immunofluorescence, and Dlx2 ${ }^{+}$cells were detected by X-gal staining of brains of Dl $x 2^{+/ \text {tauLac } Z}$ mice. Previous characterization of Dl $x 2^{+/ \text {tauLacZ }}$ brains revealed that tauLacZ expression in these animals recapitulates normal Dlx2 expression (Corbin et al., 2000; Nery et al., 2003). Of these two populations, Pax6 ${ }^{+}$cells exited the CSB and migrated to the basolateral telencephalon before Dlx ${ }^{+}$cells, with a number of $\mathrm{Pax}^{+}$cells present in the region of the developing piriform cortex by as early as E11.5 (Fig. $1 A)$. Migration of Pax6 ${ }^{+}$cells appeared most robust at midneurogenesis (Fig. $1 B, C$ ). Intense Pax6 immunoreactivity was observed in basal telencephalic cells, although its expression appeared to be partially downregulated en route to these destinations (Figs. $1 B, 2 A$ ). In contrast, the Dlx $2^{+}$population did not 


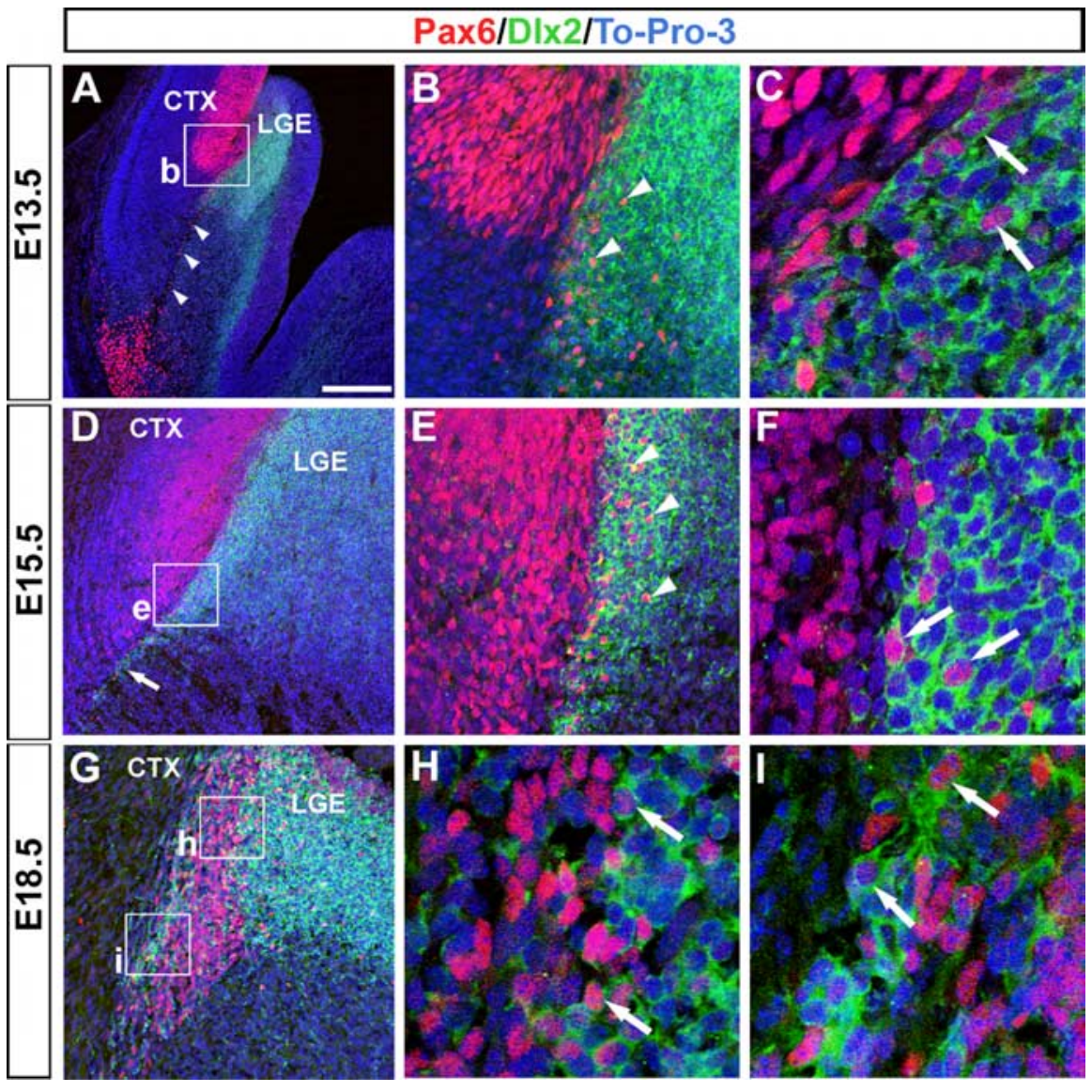

Figure 2. Dlx2 and Pax6 expression at the corticostriatal border. At E13.5, Pax6 ${ }^{+}$cells (red) are shown emanating from the border with DIx2 ${ }^{+}$cells (green) and migrating along the LCS (arrowheads) to the developing piriform cortex $(\boldsymbol{A})$. Higher magnification of the boxed region in $(\boldsymbol{A})$ revealed numerous Pax6 ${ }^{+}$cells (arrowheads) in the Dlx2 ${ }^{+}$subpallium $(\boldsymbol{B})$. Many of these $\mathrm{Pax}^{+}{ }^{+}$cells also expressed Dlx2 (arrow), in which a Pax6 ${ }^{+}$nucleus was surrounded by a Dlx2 ${ }^{+}$cell body as shown in $\boldsymbol{C}$. AtE15.5, the LCS consisted of both Dlx2 ${ }^{+}$and Pax6 ${ }^{+}$cells (arrow) (D). Higher magnification of the boxed region in $\boldsymbol{D}$ also revealed numerous Pax6 ${ }^{+}$cells in the subpallium (arrowheads), many of which expressed Dlx2 ${ }^{+}$(F, arrows). AtE18.5, Pax6 ${ }^{+}$and Dlx2 $^{+}$ cells were intermingled in both the pallial and subpallial aspects of the border $(\boldsymbol{G})$. High magnification of the boxed regions in $\boldsymbol{G}$ revealed numerous Pax6 ${ }^{+}$and Dlx2 ${ }^{+}$cells intermingled throughout the border region $(\boldsymbol{H}, \boldsymbol{I}$, arrows). In each case, To-Pro-3 iodide (To-Pro-3; blue) staining was used to label individual cell nuclei. Scale bar: $\boldsymbol{A}, 200 \mu \mathrm{m} ; \boldsymbol{B}, 50 \mu \mathrm{m} ; \boldsymbol{C}, \boldsymbol{F}, \boldsymbol{H}, \boldsymbol{I}, 20 \mu \mathrm{m} ; \boldsymbol{D}, 100$ $\mu \mathrm{m} ; \boldsymbol{E}, 35 \mu \mathrm{m} ; \boldsymbol{G}, 80 \mu \mathrm{m}$. CTX, Cerebral cortex.

begin to emerge from the CSB until $\sim 2 \mathrm{~d}$ later at E13.5 (Figs. $1 D$, $2 A)$. Similar to the $\mathrm{Pax}^{+}$population, a robust stream of $\mathrm{Dlx} 2^{+}$ migratory cells was observed along the LCS by mid-neurogenesis (Fig. $1 E$ ), with migration of both populations completed by early postnatal ages (data not shown). Both $\mathrm{Pax}^{+}$and Dlx2 ${ }^{+}$populations appeared to migrate to specific emerging amygdala nuclei and other basal telencephalic structures. By E15.5, Pax6 ${ }^{+}$cells were observed accumulating in the prospective basolateral complex, cortical and basomedial nuclei of the amygdala, as well as the olfactory tubercle and ventral pallidum, with a few cells also present in the piriform cortex (Fig. $1 B, C$ and data not shown). Interestingly, similar to the $\mathrm{Pax}^{+}{ }^{+}$cells, $\mathrm{Dlx} 2^{+}$cells putatively arising from the LCS were also observed accumulating in the basolateral complex, basomedial and cortical nuclei of the amygdala, and the piriform cortex (Figs. 1E,F, 2A) (see Figs. 4I, $8 E$ and data not shown).

The corticostriatal border is a complex mix of $\operatorname{Pax}^{+}$and Dlx2 ${ }^{+}$cells

During development, the Pax $6^{+}$and Dlx $2^{+}$cells of the LCS emanate from the CSB. To investigate the cellular composition of this border during the time course of migration along the LCS, we performed double immunostaining to visualize Pax6 ${ }^{+}$ and Dlx $2^{+}$cells. In these and all other experiments described below, Pax6 ${ }^{+}$cells were detected using Pax6 antibodies, whereas Dlx2 ${ }^{+}$cells were detected using antibodies to $\beta$-galactosidase in sections from Dlx $2^{+/ \text {tauLac } Z}$ mice. At E11.5 and E13.5, Pax6 ${ }^{+}$cells migrated along the LCS to the region of the developing piriform cortex (Figs. 1B, 2A). Higher magnification of CSB region interestingly revealed numerous $\mathrm{Pax}^{+}$cells in the subpallial Dlx2 ${ }^{+}$region (Fig. $2 B$ ), with many of these cells coexpressing Dlx2 (Fig. 2C). At E15.5, when prominent cell Dlx $2^{+}$migration occurred along the LCS (Figs. $1 E$, 2D), Pax6/Dlx2 double-labeled cells continued to be observed in the subpallium and along the proximal LCS (Fig. 2E,F). In contrast, at E13.5 and E15.5, Dlx2 ${ }^{+}$ cells were absent from the Pax6 ${ }^{+}$pallial side of border (Fig. 2B-F). At E18.5, the composition of the CSB dramatically changed, with multiple Pax6/Dlx2 coexpressing cells intermingled throughout the CSB and LCS (Fig. 2G,H) (see Fig. 4E-G).

\section{Expression of proliferative and postmitotic markers in the LCS}

To further characterize the migrating cells of the LCS, Pax6 or Dlx2 immunolabeling was combined with Ki67 (Dlx2 only) or TUJ1 to determine whether LCS subpopulations were proliferative or postmitotic, respectively. To facilitate Pax6 immunolabeling with a cell cycle marker, we also labeled S-phase cells in vivo by BrdU administration and short-term survival $(2 \mathrm{~h})$ at E15.5, the time point of robust migration along the LCS of both cell populations. At E15.5 and E18.5, a subpopulation of Dlx ${ }^{+}$cells of the LCS was proliferating (Fig. $3 A, B$ and data not shown) as indicated by colocalization with Ki67. The percentages of proliferating Dlx2 ${ }^{+}$ cells along the LCS were as follows: at E15.5, 25\% (79 of 314; $n=$ 4 brains) of cells were double Dlx $2^{+} / \mathrm{Ki}^{+} 7^{+}$, and, at E18.5, $28 \%$ ( 60 of $212 ; n=3$ brains) of cells were double positive. Analysis of the Pax6 population at E15.5 also revealed that 36\% (83 of 234; $n=4$ brains) of Pax $6^{+}$cells along the LCS continued to proliferate during migration (supplemental Fig. 1, available at www. jneurosci.org as supplemental material). Furthermore, at least a subset of Dlx $2^{+}$cells will differentiate into neurons because $16 \%$ ( 30 of $187 ; n=3$ brains) and $11 \%$ ( 6 of $48 ; n=3$ brains) of Dlx $2^{+}$ cells expressed TUJ1 at E15.5 and E18.5, respectively (Fig. 3C,D and data not shown). Similarly, some Pax6 ${ }^{+}$cells will differentiate into neurons because $8 \%$ ( 26 of $324 ; n=4$ brains), $9 \%$ ( 51 of $554 ; n=5$ brains $)$, and $9 \%$ ( 17 of $190 ; n=2$ brains $)$ of Pax $6^{+}$cells coexpressed TUJ1 at E13.5, E15.5, and E18.5, respectively (Fig. $3 E, F$ and data not shown). It is important to note, however, that because Pax6 and Dlx 2 typically mark cells in an undifferentiated state, the percentages of Pax $6^{+}$and Dlx $2^{+}$cells that will actually differentiate into neurons may be higher. Together, these exper- 

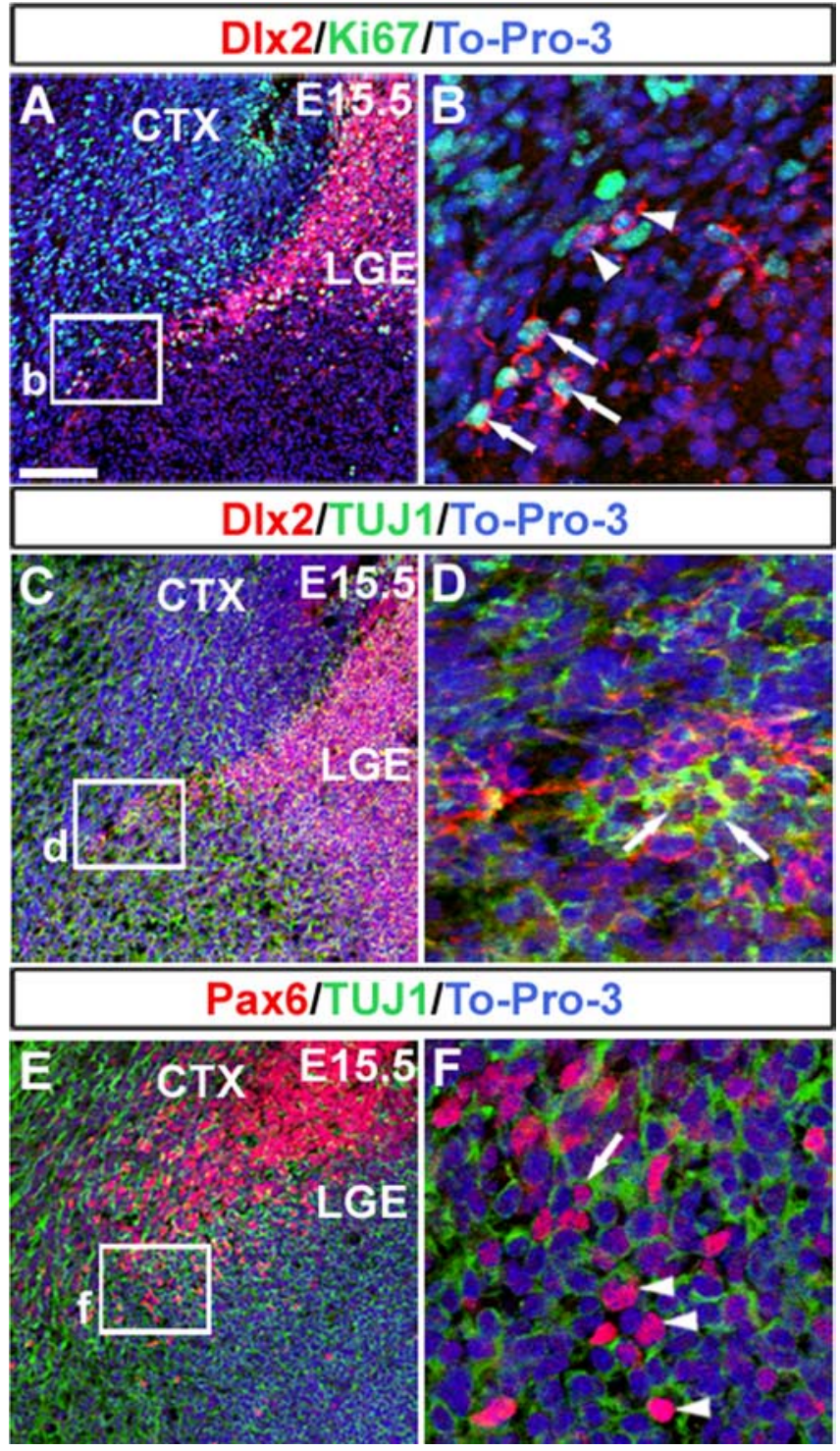

Figure 3. Expression of TUJ1 and Ki67 in the lateral cortical stream. AtE15.5, Dlx2 ${ }^{+}$cells are shown migrating along the LCS (red) through a region of Ki67 ${ }^{+}$proliferating cells (green, $A$ ). Higher magnification of boxed area in $\boldsymbol{A}$ revealed that some Dlx2 ${ }^{+}$cells were also $\mathrm{Ki}^{+}{ }^{+}$, as indicated by a Dlx2 ${ }^{+}$cell body surrounding a Ki67 ${ }^{+}$nucleus (arrows), whereas other Dlx2 ${ }^{+}$ cells were Ki67 negative (arrowheads, $\boldsymbol{B}$ ). At this same age, Dlx2 ${ }^{+}$(red) cells of the LCS migrated into a high TUJ1 (green) expressing region ( $\boldsymbol{C}$. Higher magnification of boxed area in $\boldsymbol{C}$ also revealed that some Dlx ${ }^{+}$cells coexpressed the neuronal marker TUJ1 (D, arrows). At E15.5, Pax6 ${ }^{+}$cells (red) were also observed migrating along the LCS into a TUJ1 ${ }^{+}$(green) region (E). Higher magnification of the boxed region in $\boldsymbol{E}$ revealed that some of these Pax6 ${ }^{+}$ cells were also $\mathrm{TUJ}{ }^{+}$(arrows), whereas others were TUJ1 negative (arrowheads, $\boldsymbol{F}$ ). Scale bar: $A, C, E, 100 \mu \mathrm{m} ; \boldsymbol{B}, \boldsymbol{D}, \boldsymbol{F}, 20 \mu \mathrm{m}$. CTX, Cerebral cortex.

iments indicate that a subset of $\mathrm{Dlx} 2^{+}$and $\mathrm{Pax} 6^{+}$cells are proliferating during migration along the LCS, and at least some of these progenitor cells will give rise to neurons in the basal telencephalon.

Pax ${ }^{+}$and Dlx $2^{+}$cells of the LCS are intermingled and putatively migrate following radial glia

We next wanted to examine the migratory route from E13.5 to E18.5, the time frame of greatest migration along the LCS, in more detail. During this window of development, a distinct $\mathrm{RC}_{2}{ }^{+}$radial glial cascade from the corticostriatal border to the ventrolateral telencephalon was observed (Fig. 4A-H). These ra-

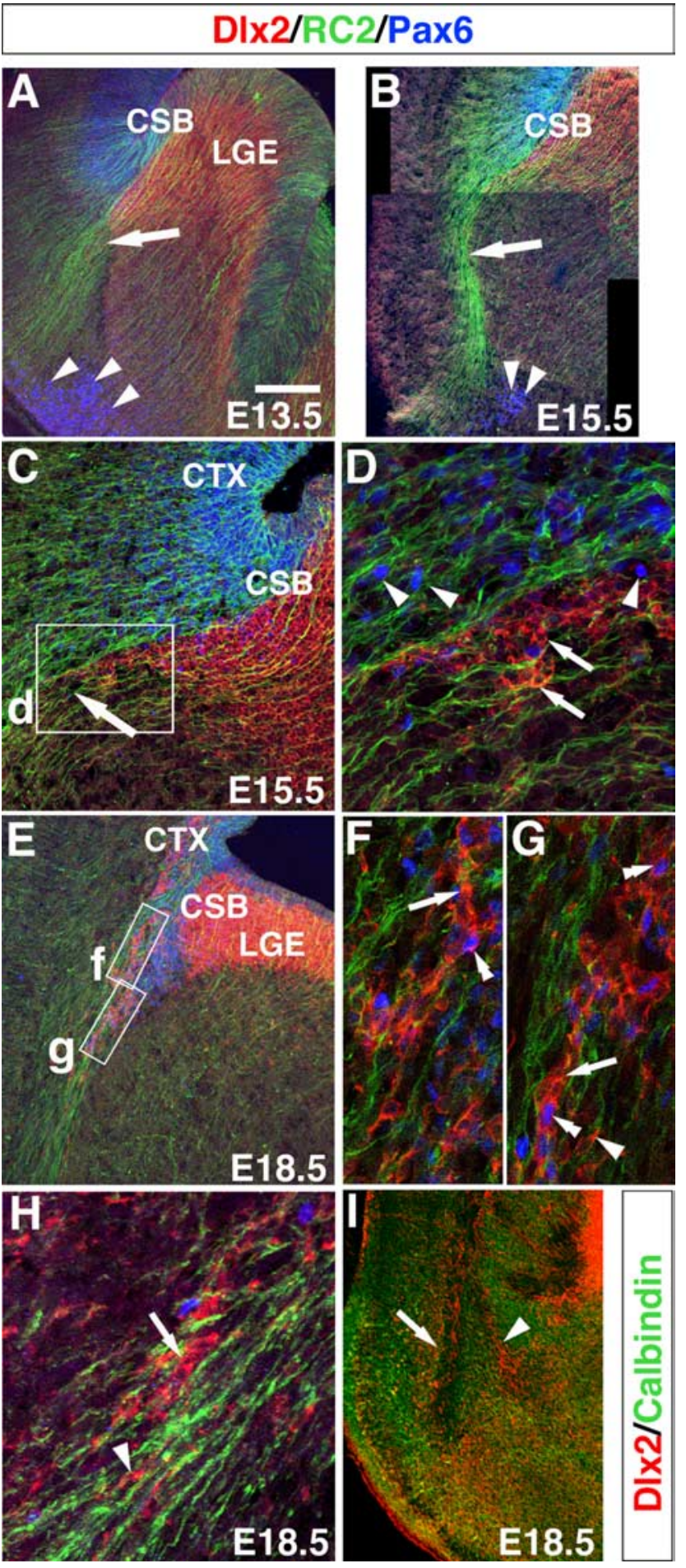

Figure 4. Route of $\mathrm{Dlx}{ }^{+}$and $\mathrm{Pax}^{+}{ }^{+}$cell migration along the LCS. As shown at $\mathrm{E} 13.5(\boldsymbol{A})$ and E15.5 (B), the route of the $L\left(C S\right.$ is marked by a prominent cascade of $\mathrm{RC}^{+}{ }^{+}$(green) radial glia (arrows). AtE13.5 and E15.5, a pool of Pax6 ${ }^{+}$cells (blue) was observed in the ventrolateral telencephalon $(\boldsymbol{A}, \boldsymbol{B}$, arrowheads). At E15.5, migrating Dlx2 ${ }^{+}$cells (red) were observed along the proximal aspect of the LCS ( $\boldsymbol{C}$, arrow). High magnification of boxed region in $\boldsymbol{C}$ revealed distinct cellular distributions of $\mathrm{Pax6}^{+}$cells (blue, arrowheads) compared with Dlx2 ${ }^{+}$cells (arrows), with Pax6 ${ }^{+}$cells dispersed widely and Dlx2 ${ }^{+}$cells more tightly packed (D). This pattern of Dlx2 ${ }^{+}$cell dispersion along the LCS was also observed at $\mathrm{E} 18.5\left(\boldsymbol{E}-\boldsymbol{H}\right.$, arrows). However, some Dlx $2^{+}$cells were also more closely associated with radial glia ( $\boldsymbol{F}-\boldsymbol{H}$, arrows) and not in packed, chain-like configurations. Additionally, a subset of cells along the LCS appeared to coexpress Pax6 and D|x2 (F, G, double arrowheads), with some of these cells in chain-like configurations. By E18.5, the Dlx2 ${ }^{+}$stream of the LCS splitinto lateral (arrow) and medial (arrowhead) routes $(\boldsymbol{H})$. These Dlx2 ${ }^{+}$(red) cells were in proximity to calbindin cells (green). CTX, Cerebral cortex. Scale bar: $\boldsymbol{A}, \boldsymbol{E}, 100 \mu \mathrm{m} ; \boldsymbol{B}, 200 \mu \mathrm{m} ; \boldsymbol{C}, 80 \mu \mathrm{m} ; \boldsymbol{D}, \boldsymbol{F}-\boldsymbol{H}, 30 \mu \mathrm{m} ; \boldsymbol{I}$, $350 \mu \mathrm{m}$. 

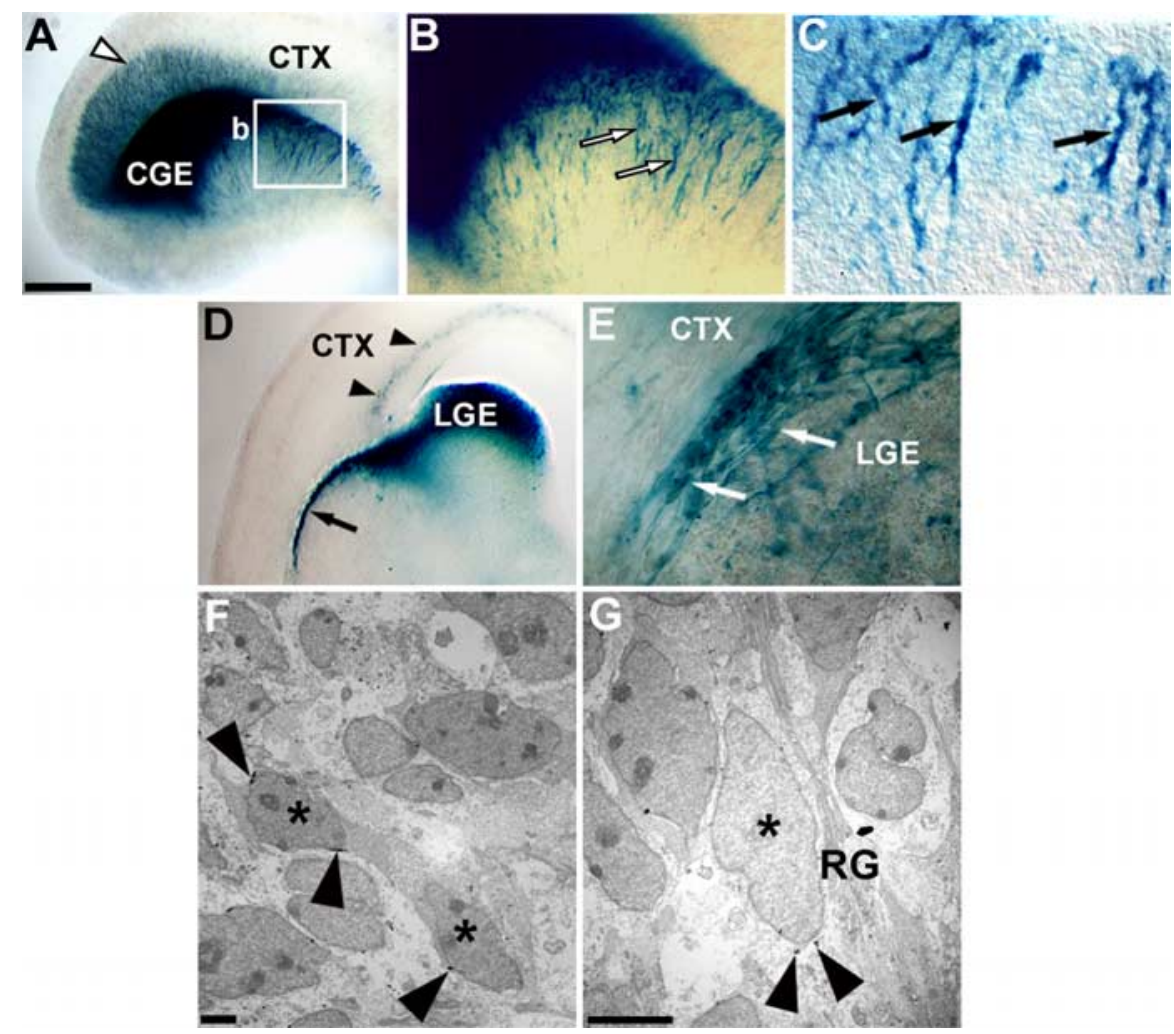

Figure 5. Dlx2 ${ }^{+}$cells of the LCS morphologically resemble chain migration in vivo. Sagittal $(\boldsymbol{A}-\boldsymbol{C})$ and coronal $(\boldsymbol{D}, \boldsymbol{E})$ views of E15.5 LacZ-stained DIX2 ${ }^{+/ \text {tauLacZ }}$ brains revealed tightly packed, chain-like cellular clusters along the LCS. In the sagittal view in $\boldsymbol{A}$, two prominent Dlx2 ${ }^{+}$migratory populations are shown; those migrating from the CGE toward the developing cortex (arrowhead) and those migrating ventrally along the LCS toward the basal telencephalon (boxed region). Higher magnification of the boxed region in $\boldsymbol{A}$ shows cascades of chain-like Dlx2 ${ }^{+}$cells emanating from the CSB region and migrating more ventrally $(\boldsymbol{B}$, arrows). High magnification of the same region from a different brain also revealed similar Dlx ${ }^{+}$chain-like configurations of cells migrating ventrolaterally ( $\boldsymbol{C}$, arrows). Similar distribution patterns of Dlx2 ${ }^{+}$cells (arrows) were also observed in coronal views of the LCS at low- $(\boldsymbol{D})$ and high- $(\boldsymbol{E})$ power views. Also note the difference in the configuration of the Dlx2 ${ }^{+}$cells of the LCS (arrow) versus Dlx2 ${ }^{+}$cells migrating to the cerebral cortex ( $\boldsymbol{D}$, arrowheads). $\boldsymbol{F}$, Electron micrographs of the LCS revealed some migrating Dlx2 ${ }^{+}$cells (asterisks) also in close apposition to each other. $\mathbf{G}$, In contrast, some Dlx2 ${ }^{+}$cells were also observed to migrate in isolation and more closely associated with radial glia. Arrowheads in $\boldsymbol{F}$ and $\boldsymbol{G}$ show perinuclear LacZ precipitate marking Dlx2 ${ }^{+}$ cells. CTX, Cerebral cortex; RG, radial glia. Scale bars: $\boldsymbol{A}, 900 \mu \mathrm{m} ; \boldsymbol{B}, 350 \mu \mathrm{m} ; \boldsymbol{C}, 150 \mu \mathrm{m} ; \boldsymbol{D}, 100 \mu \mathrm{m} ; \boldsymbol{E}, 25 \mu \mathrm{m} ; \boldsymbol{F}, \boldsymbol{G}, 4 \mu \mathrm{m}$.

dial glia are clearly evident at E13.5 and E15.5 and extended from the CSB to the ventrolateral telencephalic pial surface, with the putative migrating cells of the LCS appearing to follow this trajectory throughout development (Fig. 4A-H). High-power examination of $\mathrm{Pax}^{+}{ }^{+}$and Dlx $2^{+}$cells in relation to the curvilinear trajectory of these radial glia revealed distinct patterns of cell dispersion. Although the Pax6 antibody only marked cell nuclei, the Pax6 ${ }^{+}$pattern of cell dispersion was suggestive of a radial mode of migration (Fig. $4 D-H$ ). In contrast, Dlx $2^{+}$cell migration appeared to be more complex. Multiple clusters of apparently migrating Dlx ${ }^{+}$cells appeared "chain-like" (Fig. $4 \mathrm{C}-\mathrm{H}$ ), similar to chain migration that has been described for the rostral migratory stream (RMS) from the striatal SVZ to the olfactory bulb (Lois et al., 1996; Wichterle et al., 1999). Interestingly, these Dlx2 ${ }^{+}$clusters, although following the route outlined by the radial glial cascade, did not appear to contact the radial glia but instead appeared embedded within the loosely packed radial glial fascicles (Fig. 4C-H) (supplemental movie 1, available at www. jneurosci.org as supplemental material). Some individual Dlx $2^{+}$ cells more closely apposed to radial glia were also observed (Fig. $4 F-H)$. Thus, it appears that the mode of migration of the Dlx $2^{+}$ cells of the LCS may be complex, perhaps comprising multiple modes of migration. By E18.5, Dlx2 ${ }^{+}$cells of the both the lateral and medial branches of the LCS were located in close proximity to cells that express the neurochemical marker calbindin (Fig. 4I), which is normally expressed in $\sim 50 \%$ of inhibitory interneurons (for review, see Markram et al., 2004). This observation is consistent with our previous data (Nery et al., 2003), which revealed that some Dlx2 ${ }^{+}$cells of the piriform cortex are calbindin ${ }^{+}$. Thus, the Dlx $2^{+}$cells of the LCS are likely to be a source of inhibitory neurons in the basal telencephalon.

\section{Ultrastructural and in vitro analysis of Dlx2 ${ }^{+}$cell migration along the LCS}

Because our above immunofluorescence analysis was suggestive that at least a subset of Dlx2 ${ }^{+}$cells of the LCS may migrate via chain migration, we further analyzed their patterns of cell dispersion in vivo by light microscopic examination of $\mathrm{X}$-gal-stained telencephalic sections and whole mounts by electron microscopy (Fig. 5), as well as by in vitro cell migration assays (Fig. 6). Cell dispersion patterns of Dlx ${ }^{+}$cells of the LCS as revealed by X-gal staining of sagittal and coronal E15.5 Dlx $2^{+ \text {tauLacZ }}$ sections and whole mounts revealed configurations of cells putatively migrating in a linked, chain-like manner, with multiple cells aligned in a row (Fig. 5A-E). Electron microscopic analysis of the LCS revealed Dlx2 ${ }^{+}$cell bodies, identified by X-gal perinuclear precipitate, in close apposition to each other in the absence of nearby radial glia (Fig. $5 F$ ), similar to the arrangements observed by fluorescent and light microscopic analyses (Figs. $4 D, F-H, 5 A-$ $E)$. Interestingly, ultrastructural analysis revealed some individual Dlx ${ }^{+}$cells in apparent contact with putative radial glia (Fig. $5 G$ ), also consistent with the immunofluorescence analysis (Fig. $4 F-H$ ) (supplemental movie 1, available at www.jneurosci.org as supplemental material), which indicated that some Dlx2 ${ }^{+}$cells may also use the radial glia as a scaffold.

Dynamic migration of Dlx2 ${ }^{+}$cells was also examined in $\mathrm{Ma}-$ trigel, a highly permissive substrate for migration. In these experiments, MGE $(n=7)$, LGE $(n=7,2$ without CSB and 5 with CSB), CGE $(n=6)$, and CSB $(n=37)$ explants were dissected from Dlx2 ${ }^{+/ t a u L a c Z}$ brains at E13.5 and cultured in Matrigel for 3-4 DIV. Explants were subsequently X-gal stained to visualize Dlx $2^{+}$migrating cells. After 3-4 DIV, Dlx2 ${ }^{+}$cells from the CSB migrated out of the explants as chains in a direction similar to the basolateral route of in vivo migration (Fig. $6 B, C$ ) (see Fig. $10 A, B, D)$. Interestingly, the in vivo pattern of $\mathrm{Dlx} 2^{+}$cell migration along the LCS also appeared distinct from that of the pallialdirected Dlx2 ${ }^{+}$migrating cells (Figs. 5D, 6A). Therefore, we next compared the dynamics of Dlx2 ${ }^{+}$cell migration from the CSB to that of other subpallial progenitor regions in vitro. In contrast to the robust migration observed from CSB explants, the LGE core (LGE minus CSB region) did not display significant migratory capacity (Fig. 4D), whereas MGE- and CGE-derived Dlx2 ${ }^{+}$cells 
migrated as loose chains (Fig. $4 E, F$ ) in a manner similar to that observed previously (Wichterle et al., 1999; Nery et al., 2002, 2003). Thus, these in vivo and in vitro results revealed that the Dlx $2^{+}$cells of the LCS have an innate capacity to migrate as chains and in a manner distinct from that of the Dlx $2^{+}$cells derived from other subpallial progenitor regions.

\section{Cells of the lateral cortical stream are predominantly generated locally at the corticostriatal border}

Currently, the source of progenitor cells that comprise the LCS is unknown. We hypothesized that the cells of the LCS may (1) originate solely from the CSB or (2) comprise a heterogeneous population with a contribution from other subpallial progenitor zones such as the MGE, LGE, and/or CGE. We examined the source of the LCS using a combination in vivo and in vitro approaches. For the in vivo approach, progenitor cells from the MGE $(n=25)$, LGE $(n=5), \operatorname{CGE}(n=10)$, and CSB $(n=$ 7) were transplanted in utero, and their contribution to the LCS was compared. In these studies, either $\mathrm{GFP}^{+}$(Fig. 7B,C) or $\mathrm{PLAP}^{+}$(Fig. 7D-I) labeled cells were isolated from transgenic donor animals and subsequently homotopically and homochronically transplanted into wild-type brains with the aid of ultrasound imaging (Fig. 7A). Although it was technically challenging to successfully target the CSB (7 of 56 surviving embryos were correctly targeted), in correctly targeted brains, numerous cells were observed migrating along the LCS in a pattern highly similar to their normal path of migration. In contrast, MGE, LGE, or CGE transplanted cells did not contribute to the LCS in vivo (Fig. 7D-I). Considering the technical difficulty in transplanting CSB cells in vivo, we further examined the migratory potential of these cells in slice culture preparations. In these experiments, E13.5 $\mathrm{GFP}^{+}$explants from the CSB or MGE were homotypically grafted into wild-type organotypic cultures, and the location of migratory cells was examined after 2 DIV. GFP ${ }^{+}$transplants to the CSB $(n=22)$ revealed numerous cells that migrated along the route of the LCS to developing basal telencephalic regions (Fig. $7 J$ ), with the majority (62\%, 60 of 97) of cell processes oriented ventrally (Fig. $7 K, N, O)$. GFP ${ }^{+}$grafts from the MGE $(n=17)$ revealed extensive cell migration, including tangential migration to the pallium and numerous cells in the basal telencephalon (Fig. $7 \mathrm{~L}$ ), consistent with previous studies (Marin et al., 2001, 2003). However, similar to the in vivo transplantation experiment (Fig. $7 D, E$ ), the $\mathrm{GFP}^{+}$cells in the region of the LCS from MGE grafts predominantly (88\%, 134 of 153) had processes oriented dorsally (Fig. $7 \mathrm{M}-\mathrm{O}$ ) and not ventrally as would be expected if these cells were en route to the basal telencephalon along the LCS. Therefore, although these MGE-derived cells were in the region of the LCS, it appeared that a vast majority of these cells were destined for the pallium. Organotypic cultures with CGE grafts $(n=6)$ did not exhibit any cell migration along the posterior LCS, because CGE-derived cells assumed a direct, ventral migratory route to the basal telencephalon (data not shown).

To further examine the potential contribution of the MGE to the LCS, we analyzed the status of Dlx $2{ }^{+}$migration in knock-out mice lacking $N k \times 2.1$ in which the MGE is lost (Sussel et al., 1999). As shown at E14.5 ( $n=6$ control, $n=6$ mutants), there was no qualitative reduction in Dlx2 ${ }^{+}$cell migration along the LCS, further indicating little or no contribution from the MGE (or $N k \times 2.1^{+}$anterior CGE) to the LCS (supplemental Fig. $2 A, B$, available at www.jneurosci.org as supplemental material). Interestingly however, at more posterior levels, ventral-directed $\mathrm{Dlx} 2^{+}$cell migration from the CGE appeared reduced in $N k \times 2.1^{-/-}$mutants (supplemental Fig. 2C,D, available at www. jneurosci.org as supplemental material).

\section{Gsh2 is required for development of the LCS}

Previous studies have revealed that Gsh2 is required for development of the LGE and pattering of the CSB (Szucsik et al., 1997; Corbin et al., 2000; Toresson et al., 2000; Yun et al., 2001). Because our above data indicated that the CSB was the source of cells of the LCS (Fig. 7) (supplemental Fig. 2, available at www. jneurosci.org as supplemental material), we therefore hypothesized that defects in CSB establishment may profoundly affect development and/or migration of the LCS. To test this hypothesis, we first examined the status of the $\mathrm{Dlx} 2^{+}$population of the LCS in Gsh2 $2^{-1-}$ mutant mice. At E15.5, in control telencephalons $(n=9)$, Dlx2 expression was observed in the ganglionic eminences and in cells of the LCS (Figs. 1E, 8A). In contrast, E15.5 


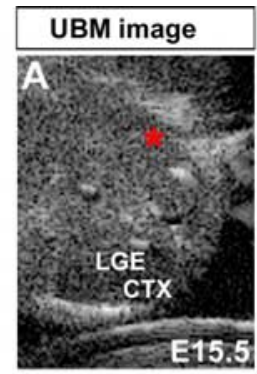

Short-term in utero transplantation
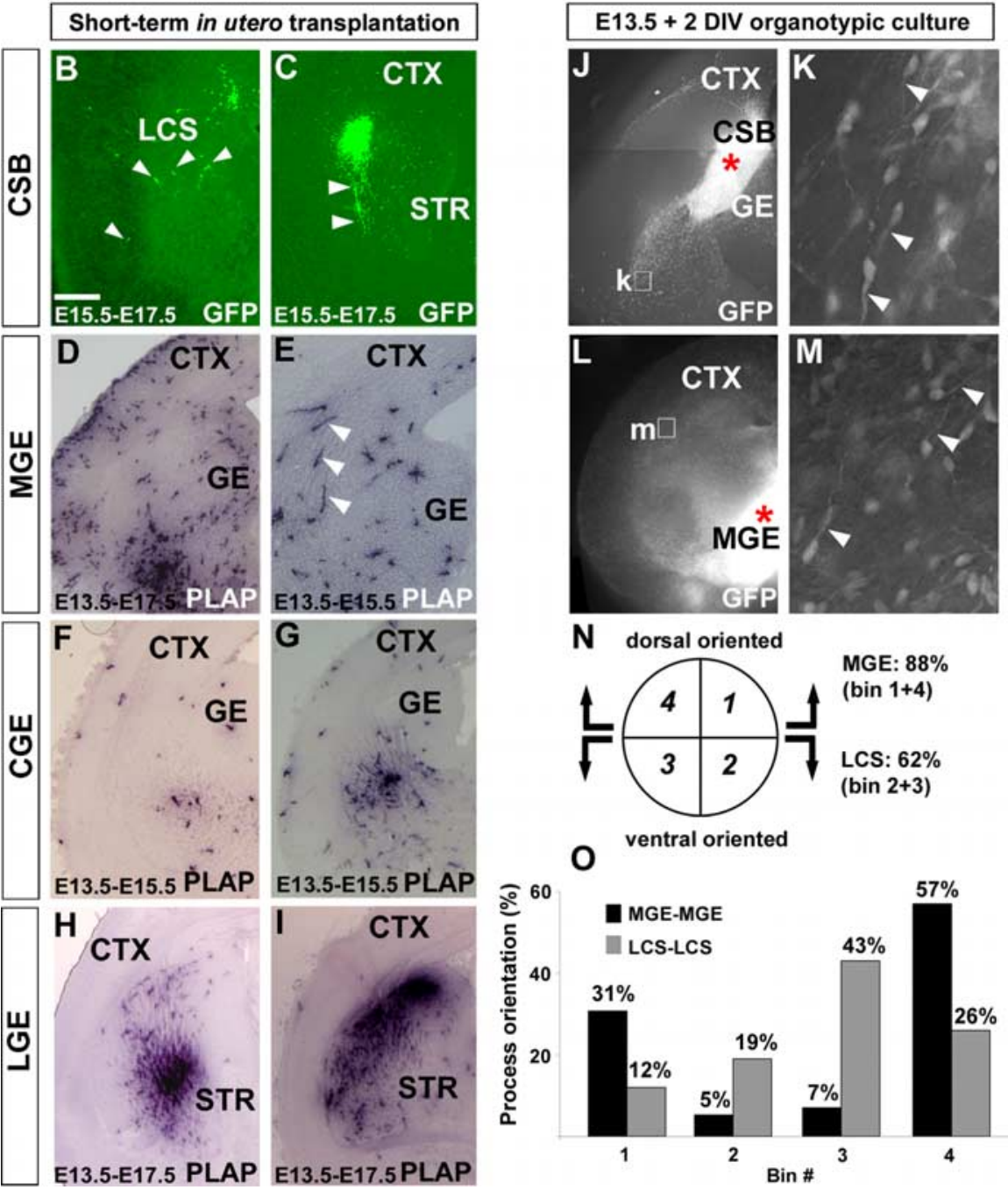

0
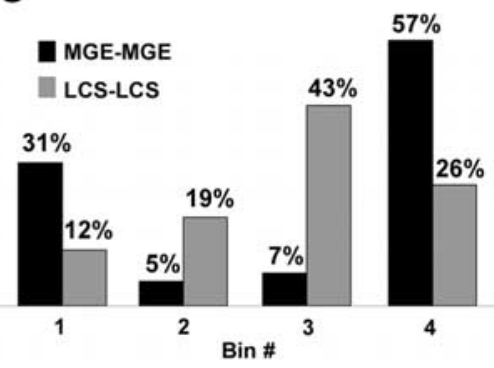

Figure 7. The corticostriatal border is the primary source of cells of the LCS. GFP $(B, C)$ or PLAP $(D-I)$ cells were homotopically transplanted at E15.5 to the $C S B(B, C)$ or at E13.5 to the MGE, CGE, or LGE $(\boldsymbol{D}-\boldsymbol{I})$ with the aid of ultrasound-guided microscopy $(\boldsymbol{A}$, asterisk indicates needle placement at (SB) and analyzed $2-4 \mathrm{~d}$ after transplantation. (SB transplanted cells migrated along the LCS ( $\boldsymbol{B}, \boldsymbol{C}$, arrowheads). In contrast, although MGE transplanted cells were also observed along the route of the $L C S(D, E)$, many of these cells possessed leading processes directed toward the developing cerebral cortex ( $\boldsymbol{E}, \boldsymbol{M}$, arrowheads). Both CGE-derived ( $\boldsymbol{F}$ $\boldsymbol{G})$ and LGE-derived $(\boldsymbol{H}, \boldsymbol{I})$ cells did not migrate along the LCS. In vitro, explants from GFP ${ }^{+}$donors were homotopically transplanted at E13.5 into wild-type coronal telencephalic organotypic slice cultures and cultured for 2 DIV. CSB transplants (asterisk shows region of transplant) revealed robust migration along the $L C S(J)$, with many cells extending a leading process in the direction of the ventrolateral telencephalon ( $\boldsymbol{K}$, arrowheads). Homotopically transplanted GFP ${ }^{+}$MGE cells were also observed along the region of the $L C S(L)$, but most of cells displayed dorsally directed leading processes ( $M$, arrowheads). Quantification of process orientation (cells were placed into 1 of 4 bins based on the direction of the leading process) revealed that $88 \%$ (134 of 153 ) of MGE cells had processes directed dorsally (bins 1,4), whereas $62 \%$ (60 of 97 ) of LCS cells had processes oriented ventrally (bins 2, 3) $(\boldsymbol{N})$. Breakdown of percentages of cells found in each bin for MGE and LCS cells is shown graphically in $\mathbf{0}$. For MGE grafts, a total of 153 cells were counted, and for CSB grafts, a total of 97 cells were counted. The numbers of cells whose process orientation fell into each bin were as follows: MGE-MGE grafts, bin 1 ( 47 cells), bin 2 ( 8 cells), bin 3 (11 cells), bin 4 (87 cells); LCS-LCS grafts, bin 1 ( 12 cells), bin 2 (18 cells), bin 3 (42 cells), bin 4 ( 25 cells). CTX, Cerebral cortex; GE, ganglion eminence; STR, striatum; Scale bar: $\boldsymbol{B}, \boldsymbol{D}, \boldsymbol{F}-\boldsymbol{I}, 250 \mu \mathrm{m} ; \boldsymbol{C}, \boldsymbol{J}, \boldsymbol{L}, 300 \mu \mathrm{m} ; \boldsymbol{E}, 125 \mu \mathrm{m} ; \boldsymbol{K}, \boldsymbol{M}, 40 \mu \mathrm{m}$.
$G s h 2^{-1-}$ mutant mice $(n=6)$ possessed only a few Dlx ${ }^{+}$cells at the proximal part of the LCS and none along the normal route of LCS migration (Fig. $8 B$ ). The perinatal lethality of $G s h 2^{-/-}$mutants precluded an examination of these animals at later time points, and, although patterning of the striatum was essentially recovered by E18.5 (Corbin et al., 2000; Toresson et al., 2000; Yun et al., 2001), analysis at E18.5 revealed that the migration of Dlx $2{ }^{+}$cells along the LCS did not recover (control, $n=3$; Gsh $2^{-/-}$mutants, $n=4$ ) (Fig. 8C-F). Furthermore, consistent with previous observations (Toresson et al., 2000; Yun et al., 2001; Stenman et al., 2003b), Gsh2 $2^{-/-}$mutants $(n=5)$ displayed a significant decrease in the number of Pax $6^{+}$cells in the basal telencephalon compared with controls $(n=3)$ as shown at E12.5 (Fig. 9C,D).

We hypothesized that the loss of Dlx $2^{+}$ cell migration along the LCS could result from a defect in the pathway in which these cells migrate (extrinsic defect), a lack of proper specification of these cells (intrinsic defect), or a combination of the two. To further explore the nature of the defect, we first examined the status of the LCS radial glia in Gsh $2^{-/-}$mutant mice. The molecular boundary separating the CSB from the pallium is located ventral to the ventricular angle, in which $\mathrm{BLBP}^{+}$ fibers of the LCS were observed in E12.5 control embryos $(n=5)$ (Fig. 9A) (Anthony et al., 2004; Yoon et al., 2004). As described previously (Corbin et al., 2000; Toresson et al., 2000; Yun et al., 2001), the loss of Gsh2 results in an expansion of pallial gene expression into the LGE at early (younger than E15.5) embryonic time points. Here, we found that $\mathrm{BLBP}^{+}$fibers appeared to have emerged more distally from the ventricular angle than in controls, indicating that the domain of $\mathrm{BLBP}^{+}$radial glia was shifted ventrally in Gsh $2^{-/-}$mutant mice $(n=6)$ (Fig. $\left.9 A, B\right)$. However, individual $\mathrm{BLBP}^{+}$or $\mathrm{RC}^{+}{ }^{+} \mathrm{fi}^{-}$ bers that extended from the CSB to the basal telencephalic pial surface exhibited no apparent abnormality in their trajectory or fasciculation, indicating that the integrity of the radial glia was maintained in $G s h 2^{-1-}$ mutant mice (Fig. 9C-F).

We also further examined whether Dlx2 ${ }^{+}$cells in Gsh2 $2^{-/-}$animals maintained their intrinsic capacity to migrate in vitro on a permissive substrate for migration. In these experiments, E13.5 CSB explants from Gsh $2^{-/-} ; D l \times 2^{+/ t a u L a c Z}$ and Gsh $2^{+/-} ; D l \times 2^{+/ \text {tauLacZ }}$ or $G s h 2^{+/+}$; Dl $x 2^{+/ \text {tauLacZ }}$ control brains were cultured in Matrigel. After 3-4 DIV, X-gal staining 


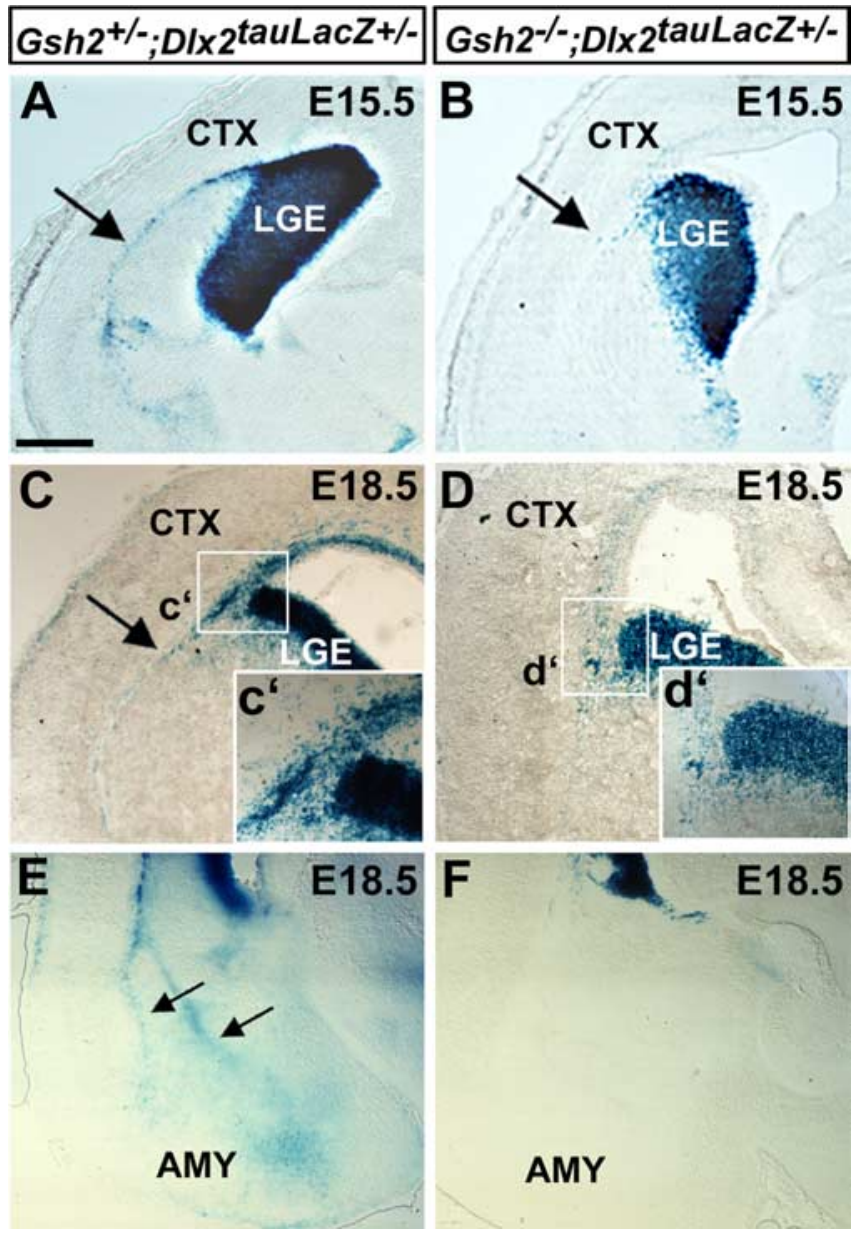

Figure 8. The LCS is significantly affected in Gsh $2^{-1-}$ mutants. Dlx2 ${ }^{+}$cell migration along the $L C S$ was reduced in $G$ sh $2^{-/-} ; D / \times 2^{+/ t a u l a c Z}$ mutant mice $(A, C, E)$ compared with controls $(\boldsymbol{B}, \boldsymbol{D}, \boldsymbol{F})$. As shown at both E15.5 $(\boldsymbol{A}, \boldsymbol{B})$ and E18.5 (C, $\boldsymbol{D})$, only a few cells were observed leaving the corticostriatal border in mutant mice compared with controls (arrows). A higher magnification of the Dlx2 expression in the CSB region in $\boldsymbol{C}$ and $\boldsymbol{D}$ is shown in $\boldsymbol{c}^{\prime}$ and $\boldsymbol{d}^{\prime}$. At E18.5, the lateral and medial branches of Dlx2 ${ }^{+}$cells that extend from the LCS into the basal telencephalon in controls ( $\boldsymbol{E}$, arrows) were not observed in $G$ sh $2^{-1-} ; D 1 \times 2^{+/ t a u l a c Z}$ mutant mice $(\boldsymbol{F})$. AMY Amygdala; CTX, cerebral cortex. Scale bar: $\boldsymbol{A}-\boldsymbol{F}, 150 \mu \mathrm{m}$.

of control explants revealed two primary migrating streams of Dlx $2^{+}$cells. Dlx $2^{+}$cells of the presumptive LCS extended ventrally from the CSB region, and Dlx2 ${ }^{+}$cells of the putative RMS emerged dorsal to the CSB (Fig. 10A-D). Cell migration in control explants ( $n=22$ animals, 77 total explants), occurred predominantly along both the presumptive RMS and LCS (79.2\%, 61 of 77 explants), although a minority of explants exhibited RMS cell migration only $(20.8 \%, 16$ of 77 explants) (Fig. 10G). In contrast, in $G s h 2^{-1-}$ mutant mice ( $n=7$ animals, 27 total explants), cell migration along both routes occurred at a much lower frequency (22.2\%, 6 of 27 explants), with RMS-only cell migration observed in the vast majority of explants $(77.8 \%, 21$ of 27 explants) (Fig. 10G). These results indicate that migratory defect along the LCS in Gsh2 $2^{-1-}$ mutant mice cannot be rescued on a permissive substrate for migration.

\section{Discussion}

The lateral cortical stream is a heterogeneous population of neural progenitor cells

During embryogenesis, the LCS arises from the CSB and migrates toward the basal telencephalon. This migratory route is accom-
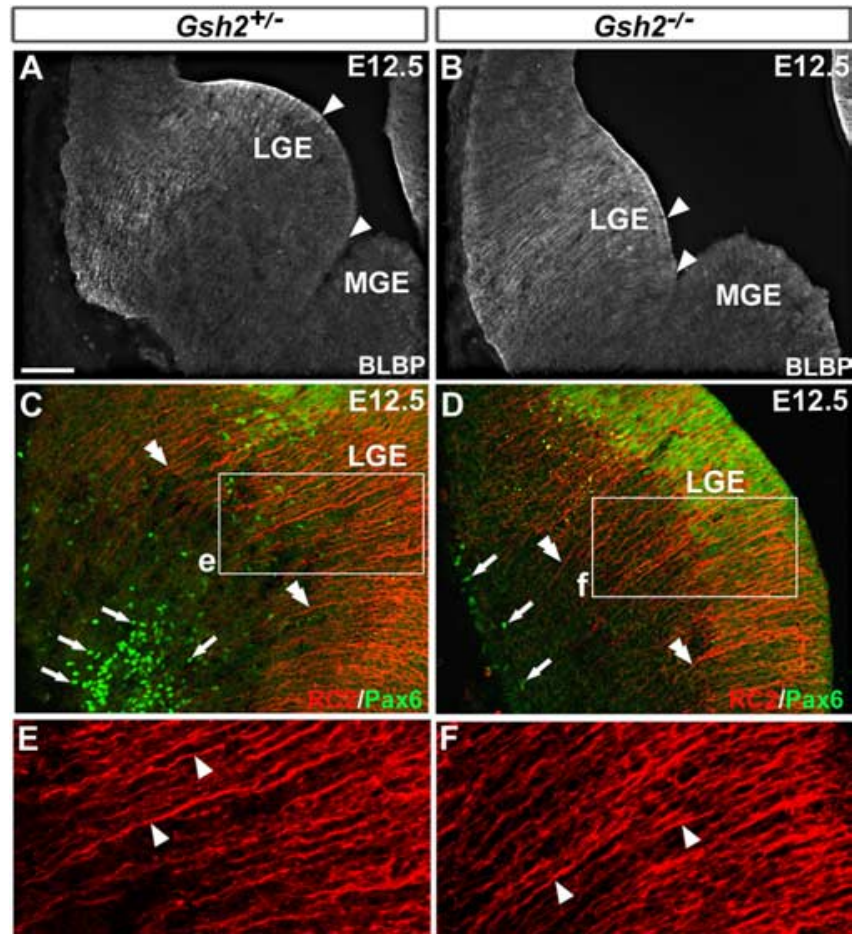

Figure 9. Status of radial glia in $G s h 2^{-\prime-}$ mutants. At E12.5, the domain of $\mathrm{BLBP}^{+}$radial glia appeared to be shifted more ventral in $G$ sh $2^{-/-}$mutants $(\boldsymbol{A}, \boldsymbol{B}$, arrowheads mark distance between lower limit of BLBP expression in the LGE and the LGE/MGE sulcus). As revealed by Pax6 immunostaining, a reduction in the number of $\mathrm{Pax}^{+}{ }^{+}$cells (green, arrows) in the ventrolateral telencephalon was observed in Gsh2 ${ }^{-/-}$mutants compared with controls $(\boldsymbol{C}, \boldsymbol{D})$. However, in Gsh2 ${ }^{-1-}$ mutants, $\mathrm{RC2}^{+}$radial glial morphology (red, double arrowheads $C, D$ and boxed regions shown in higher magnification in $\boldsymbol{E}, \boldsymbol{F}$ ) appeared normal. Scale bar (in $\boldsymbol{A}): \boldsymbol{A}, \boldsymbol{B}, 150 \mu \mathrm{m}$; $C, D, 50 \mu \mathrm{m} ; E, F, 20 \mu \mathrm{m}$

panied by the presence of radial glia that forms a circumferential fiber band that extends to the ventrolateral telencephalon (Smart and Sturrock, 1979; Misson et al., 1988; Edwards et al., 1990). Although it has been suggested that the LCS provides cells to the ventrolateral neocortex, piriform cortex, endopiriform nucleus, claustrum (Bayer and Altman, 1991), and the dense cell layer of the olfactory tubercle (Tamamaki et al., 2001), little is known regarding the developmental profile of this migratory stream and the genetic factors governing its development. Here, consistent with previous studies (Stoykova et al., 1996; Puelles et al., 2000; Hirata et al., 2002; Tole et al., 2005), we show that the LCS is a heterogeneous population comprised of separate pallial Pax $6^{+}$derived and subpallial Dlx $2^{+}$-derived cells. Our data also interestingly indicate that the LCS is comprised of an additional population of progenitor cells that coexpress both pallial (Pax6) and subpallial (Dlx2) markers.

Based on the known developmental potential of the pallium and the subpallium, it is reasonable to hypothesize that the Pax6 ${ }^{+}$ cells of the LCS will give rise to excitatory cells of the basal telencephalic limbic system and the Dlx $2^{+}$cells will give rise to inhibitory neurons. If this turns out to be the case, the migration of this combined population along the LCS would be an exception to other migratory routes in the forebrain whereby putative excitatory and inhibitory cell populations migrate independently (for review, see Corbin et al., 2001; Marin and Rubenstein, 2001; Monuki and Walsh, 2001). The ultimate fate of the cells that coexpress both Pax6 and Dlx2 is, however, less straightforward to predict. Based on this dual-marker expression, these cells appear to represent a subpopulation of progenitors of mixed pallial and 


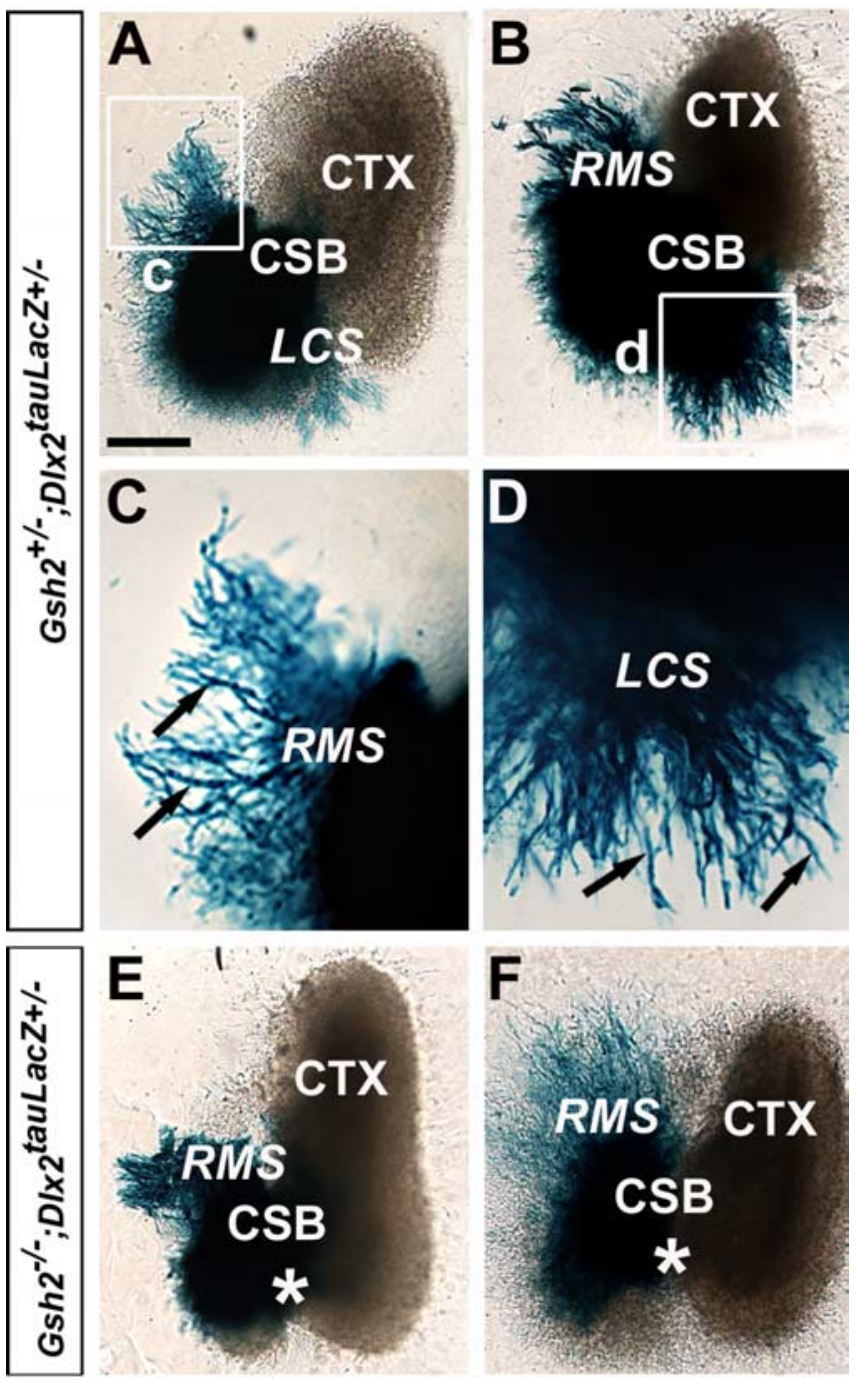

Figure 10. The defect in Dlx2 ${ }^{+}$migration in Gsh $2^{-/-}$mutants along the LCS is not rescued in vitro. Telencephalic explants of the CSB region were dissected from Gsh2 $2^{-/-} ; D / \times 2^{+/ \text {taulacz }}$ and control animals at E13.5 and were cultured on Matrigel for 3-4 d, fixed, and subsequently LaCZ stained. In control brains (A-D), robust, DlX2 ${ }^{+}$chain-like migration was observed along the presumptive LCS and RMS. Boxed regions in $\boldsymbol{A}$ and $\boldsymbol{B}$ are shown at higher magnification in $\boldsymbol{C}$ and $\boldsymbol{D}$, respectively. Arrows in $\boldsymbol{C}$ show tight chains of putative RMS migrating Dlx $2^{+}$cells. Arrows in $\boldsymbol{D}$ show chains of Dlx ${ }^{+}$putative LCS cells. A reduced number of explants from Gsh2 $2^{-/-} ; D 1 \times 2^{+/ \text {taulacz }}$ mice $(\boldsymbol{E}, \boldsymbol{F})$, displayed migration along the LCS. The asterisk indicates region of expected LCS migration in mutant explants. In controls ( $n=22$ animals, 77 explants), $79.2 \%$ of explants displayed migration along both RMS and LCS, whereas in Gsh2 ${ }^{-1-}$; D/ $\times 2^{+/ \text {taulacz }}$ mutants ( $n=7$ animals, 27 explants), only $22.2 \%$ of explants displayed migration along both RMS and LCS. Scale bar: $\boldsymbol{A}, \boldsymbol{B}, \boldsymbol{E}, \boldsymbol{F}, 250 \mu \mathrm{m} ; \boldsymbol{C}, \boldsymbol{D}, 100 \mu \mathrm{m}$.

subpallial phenotype that migrate to the ventrolateral telencephalon. However, it is possible that these cells are derived from the subpallium, which as observed previously (Puelles et al., 2000; Yun et al., 2001), also expresses low levels of Pax6. Thus, this coexpressing population may in fact be a unique subpopulation of subpallial-derived cells distinct from the subset of progenitors that only express Dlx2. However, if indeed these cells are subpallial in origin, they still may be fated to a GABAergic phenotype. Alternatively, because there is a much larger population of cells that expresses both pallial and subpallial markers at the CSB (Corbin et al., 2003), earlier in development before the LCS emerges $(\sim \mathrm{E} 10.5)$, it is also possible that these later Pax6/Dlx2 coexpressing cells are derived from these earlier coexpressing border cells.
Regardless of their pallial, subpallial, or mixed origin, the majority of migrating cells of the LCS appear to contribute to the amygdala, a major structure of the mammalian limbic system. The amygdala (or amygdalar complex) is a highly differentiated and complex region of the basal telencephalon and is comprised of at least 10 functionally and anatomically distinct subnuclei (for review, see Price et al., 1987; Alheid, 2003). Previous analysis of the composition of the distinct amygdala nuclei revealed that they can be grouped into two basic functional subdivisions: those that possess excitatory neurons and those that possess inhibitory projection neurons (inhibitory interneurons are dispersed throughout all amygdala nuclei) (for review, see Swanson and Petrovich, 1998). Thus, at the cellular level, the amygdala shares similarities with both the cerebral cortex and the striatum. This observation has lead to a model proposed by Swanson and Petrovich (1998), which hypothesized that the amygdala is comprised of both pallial- and subpallial-derived cells. Genetic and transplantation-based fate mapping of both pallial-derived (Gorski et al., 2002) and subpallial-derived (Nery et al., 2002; Stenman et al., 2003a) progenitor cells, as well as gene expression studies (Fernandez et al., 1998; Puelles et al., 1999, 2000; Zirlinger et al., 2001; Medina et al., 2004; Remedios et al., 2004; Tole et al., 2005), have lent significant credence to this model. Our observations in the present study are also consistent with this model, because the LCS appears to be a major source of both pallial- and subpallialderived cells of the amygdala. Furthermore, although LCS cells migrate to numerous other ventral telencephalic structures, in agreement with previous studies (Stoykova et al., 1996; Tole et al., 2005), we observe $\mathrm{Pax}^{+}$and $\mathrm{Dlx} 2^{+}$cells populating distinct subsets of developing amygdala nuclei such as the basolateral complex and basomedial and cortical nuclei. Furthermore, colocalization of both $\mathrm{Pax}_{6}{ }^{+}$and Dlx $2^{+}$cells with the early neuronal marker TUJ1 indicates that at least some of these cells will differentiate into neurons. Considering that previous studies have also indicated that progenitor cells of the CSB also have a potential to develop into cortical astrocytes and oligodendrocytes (Marshall and Goldman, 2002), it will be important to determine whether cells of the LCS also give rise to basal telencephalic glia.

\section{Cells of the lateral cortical stream display distinct migratory characteristics}

Our data indicate that $\mathrm{Pax}^{+}{ }^{+}$and Dlx $2{ }^{+}$cells of the LCS migrate as a mixed population following the curvilinear trajectory of the radial glia scaffold. The pattern of $\mathrm{Pax}^{+}{ }^{+}$cell dispersal and locations along the LCS indicate that these cells migrate along the radial glial scaffold. Interestingly, in contrast, our in vivo and in vitro analyses of the Dlx $2^{+}$population suggest that migration of this population is more complex. Although we have yet to demonstrate definitive chain migration in time-lapse microscopy studies, our multiple in vitro and in vivo analyses strongly indicate that chain migration represents a major mode of migration via which these cells transit to their final destinations in the basal telencephalic limbic system. To date, the only identified chain migrating progenitor population in the telencephalon is the RMS, the source of replenishing olfactory bulb interneurons throughout adulthood (Luskin, 1993; Lois and Alvarez-Buylla, 1994; Doetsch and Alvarez-Buylla, 1996; Alvarez-Buylla and Garcia-Verdugo, 2002). The reason cells use different modes of migration is unclear, although the differential speed at which chain versus radial migration occur may be important. For example, chain migrating cells of the RMS travel approximately three times faster than radially migrating cells, indicating the former mode as a more effective means to rapidly transit cells to their 
final destinations (Wichterle et al., 1997). We further show that the timing of the migration of these separate populations is distinct, with the onset of Pax $6^{+}$cell migration along the LCS preceding that of the Dlx $2^{+}$population by $\sim 2 \mathrm{~d}($ E11.5 vs E13.5). Thus, conceivably $\mathrm{Dlx} 2^{+}$cells may use chain migration as a means to populate basal telencephalic regions more rapidly. Our data also reveal that the putative chain migrating Dlx $2{ }^{+}$cells of the LCS, although closely associated with the radial glia guide, do not appear to migrate along this substrate. Thus, perhaps these radial glia provide a permissive environment for directed migration to the basal telencephalon similar to the role of the glial tube in the chain migration of RMS progenitors to the olfactory bulb. In addition to this apparent chain-like migration, a number of Dlx2 ${ }^{+}$cells that were observed along the LCS appeared less as chains but as individual cells more closely associated with radial glia, indicating that the mode of migration of Dlx $2^{+}$cells is likely complex. It will be interesting to explore whether these putative differences represent separate subpopulations of migrating $\mathrm{Dlx} 2{ }^{+}$progenitors or whether individual Dlx $2^{+}$cells use both chain and radial migration as they transit to the basal telencephalon. It is also important to note that the chain-like appearance of $\mathrm{Dlx} 2{ }^{+}$cells from the CSB, both in vivo and in vitro, contrasted to the loose chains that emanated from the MGE or CGE and is in agreement with regional subpallial variation in migratory capacity (Wichterle et al., 2001; Nery et al., 2003).

\section{The lateral cortical stream is generated locally at the corticostriatal border progenitor zone}

Emerging spatiotemporal patterns of gene expression suggest that embryonic telencephalic regions undergo a developmental parcellation according to predefined genetic codes (for review, see Rallu et al., 2002; Campbell, 2003; Puelles and Rubenstein, 2003). Recently, it has been shown that the spatial and temporal origin of subpallial precursors predicts the mature physiological properties of interneurons in the somatosensory cortex (Butt et al., 2005), thus revealing a functional component to the regional identity of subpallial progenitor zones such as the MGE and CGE. Such early specification of neural progenitors predicts that each telencephalic progenitor zone will be a source of cells with distinct functional characteristics in the mature brain. This (Butt et al., 2005) and other work (Stenman et al., 2003a) has also interestingly revealed that the CGE and LGE can be further subdivided into subregions with distinct developmental capacity.

The CSB is marked by a number of genes whose expression is restricted to this region (e.g., Dbx1, Sfrp2, Er81, Sp8, and Tsh1) (Lu et al., 1996; Kim et al., 2001; Stenman et al., 2003a; Caubit et al., 2005; Waclaw et al., 2006), indicating that the CSB may also be a unique progenitor zone in the developing telencephalon. One prediction of this is that progenitor cells of the LCS are generated locally at the CSB and not imported from the other telencephalic progenitor zones (e.g., MGE, LGE, or CGE). Indeed, our shortterm fate mapping of in utero transplanted progenitor cells, cell tracking in organotypic cultures, in vitro Matrigel cultures, and analysis of $N k \times 2.1$ mutant mice revealed that the MGE, LGE, or CGE contributes little to the LCS. Because telencephalic neural progenitors are specified early and functionally differentiate according to their regional origin (Nery et al., 2002; Xu et al., 2004; Butt et al., 2005), we further postulate that locally generated CSB cells that form the LCS will in turn have their own intrinsic physiological characteristics in the mature basal telencephalic limbic system. Such specification may in part or wholly underlie the preferential localization of Pax6 ${ }^{+}$and Dlx $2^{+}$cells in emerging amygdaloid nuclei as observed in the present study.
Our previous in utero transplantation studies have shown that other subpallial progenitors (specifically those arising from the MGE and CGE) also generate cells destined for the amygdala (Nery et al., 2002), indicating that there are multiple embryonic sources of amygdala cells. Thus, similar to the apparent mechanism of the generation of cellular diversity in the cerebral cortex, it is likely that the basal telencephalic limbic system is contributed to by a number of distinct subpallial and pallial telencephalic progenitor regions, including the CSB. Thus, together these data should have broad implications for unraveling the developmental origins of cellular diversity in the mature amygdala.

\section{Gsh2 is required for the generation of the lateral cortical stream}

Gsh2 is essential for the specification of the dorsal LGE and correct positioning of the CSB (Corbin et al., 2000; Toresson et al., 2000; Yun et al., 2001). Previous studies have also indicated that Gsh2 is also required for proper specification and/or migration of the Pax $6^{+}$population of the LCS (Toresson et al., 2000; Yun et al., 2001; Stenman et al., 2003c). Here, we found that, in addition to the defect in Pax ${ }^{+}$cells, the Dlx $2^{+}$component of the LCS was entirely absent in $G s h 2^{-/-}$mutant mice. Interestingly, although proper CSB border positioning is reestablished by midneurogenesis in Gsh2 $2^{-/-}$mutants (Corbin et al., 2000; Toresson et al., 2000; Toresson and Campbell, 2001; Yun et al., 2001), the loss of Dlx ${ }^{+}$cells along the LCS, unlike the olfactory bulb interneuron defect in these mice, does not partially recover. This may reflect that fact that cells of the basal telencephalic limbic system appear to be specified during a fixed window of development (McConnell and Angevine, 1983; Bayer and Altman, 1991; present study), whereas olfactory bulb neurogenesis continues through adulthood (for review, see Alvarez-Buylla and GarciaVerdugo, 2002).

The inability to rescue the $\mathrm{Dlx} 2^{+}$migratory defect in our Matrigel experiment indicates that one function of Gsh2 is in the specification of Dlx $2^{+}$population of the LCS or in the regulation of the capacity of these cells to migrate. However, the function of Gsh2 in the generation of the LCS may be more complex. For example, although our data indicate that the integrity and fasciculation of the LCS radial glia is normal in $G s h 2^{-/-}$mutants, more subtle abnormalities in radial glial function cannot be ruled out (e.g., the loss of secreted factors that may promote Dlx ${ }^{+}$chain migration). Indeed, the ventral shift of $\mathrm{BLPB}^{+}$radial glia in $G s h 2$ mutants indicates that this may be the case. Thus, the potential function of Gsh2 in both the specification of migratory progenitor cells of the LCS and of the radial glial guide warrants additional investigation.

In summary, our data indicate that the LCS is a complex migratory route comprising distinct subtypes of neural progenitor cells that contribute to distinct basal telencephalic nuclei. Thus, determining the genetic cascades required for the specification of this cell population and the ultimate fate of these cells in the mature brain will have broad implications for unraveling the developmental logic underlying the generation of neuronal cell diversity in the developing basal telencephalic limbic system and in particular the amygdala.

\section{References}

Alheid GF (2003) Extended amygdala and basal forebrain. Ann NY Acad Sci 985:185-205.

Alvarez-Buylla A, Garcia-Verdugo JM (2002) Neurogenesis in adult subventricular zone. J Neurosci 22:629-634.

Anthony TE, Klein C, Fishell G, Heintz N (2004) Radial glia serve as neuro- 
nal progenitors in all regions of the central nervous system. Neuron 41:881-890.

Assimacopoulos S, Grove EA, Ragsdale CW (2003) Identification of a Pax6dependent epidermal growth factor family signaling source at the lateral edge of the embryonic cerebral cortex. J Neurosci 23:6399-6403.

Bayer S, Altman J (1991) Neocortical development. New York: Raven.

Butt SJ, Fuccillo M, Nery S, Noctor S, Kriegstein A, Corbin JG, Fishell G (2005) The temporal and spatial origins of cortical interneurons predict their physiological subtype. Neuron 48:591-604.

Campbell K (2003) Dorsal-ventral patterning in the mammalian telencephalon. Curr Opin Neurobiol 13:50-56.

Caubit X, Tiveron MC, Cremer H, Fasano L (2005) Expression patterns of the three Teashirt-related genes define specific boundaries in the developing and postnatal mouse forebrain. J Comp Neurol 486:76-88.

Corbin JG, Gaiano N, Machold RP, Langston A, Fishell G (2000) The Gsh2 homeodomain gene controls multiple aspects of telencephalic development. Development 127:5007-5020.

Corbin JG, Nery S, Fishell G (2001) Telencephalic cells take a tangent: nonradial migration in the mammalian forebrain. Nat Neurosci [Suppl] 4:1177-1182.

Corbin JG, Rutlin M, Gaiano N, Fishell G (2003) Combinatorial function of the homeodomain proteins $\mathrm{Nkx} 2.1$ and Gsh2 in ventral telencephalic patterning. Development 20:4895-4906.

de Carlos JA, Lopez-Mascaraque L, Valverde F (1996) Dynamics of cell migration from the lateral ganglionic eminence in the rat. J Neurosci 16:6146-6156.

DePrimo SE, Stambrook PJ, Stringer JR (1996) Human placental alkaline phosphatase as a histochemical marker of gene expression in transgenic mice. Transgenic Res 5:459-466.

Doetsch F, Alvarez-Buylla A (1996) Network of tangential pathways for neuronal migration in adult mammalian brain. Proc Natl Acad Sci USA 93:14895-14900.

Edwards MA, Yamamoto M, Caviness Jr VS (1990) Organization of radial glia and related cells in the developing murine CNS. An analysis based upon a new monoclonal antibody marker. Neuroscience 36:121-144.

Fernandez AS, Pieau C, Reperant J, Boncinelli E, Wassef M (1998) Expression of the Emx-1 and Dlx-1 homeobox genes define three molecularly distinct domains in the telencephalon of mouse, chick, turtle and frog embryos: implications for the evolution of telencephalic subdivisions in amniotes. Development 125:2099-2111.

Gorski JA, Talley T, Qiu M, Puelles L, Rubenstein JL, Jones KR (2002) Cortical excitatory neurons and glia, but not GABAergic neurons, are produced in the Emx1-expressing lineage. J Neurosci 22:6309-6314.

Hicks SP, D'Amato CJ (1968) Cell migrations to the isocortex in the rat. Anat Rec 160:619-634.

Hirata T, Nomura T, Takagi Y, Sato Y, Tomioka N, Fujisawa H, Osumi N (2002) Mosaic development of the olfactory cortex with Pax6-dependent and -independent components. Brain Res Dev Brain Res 136:17-26.

Kim AS, Anderson SA, Rubenstein JL, Lowenstein DH, Pleasure SJ (2001) Pax-6 regulates expression of SFRP- 2 and Wnt-7b in the developing CNS. J Neurosci 21:RC132(1-5).

Liu A, Joyner AL, Turnbull DH (1998) Alteration of limb and brain patterning in early mouse embryos by ultrasound-guided injection of Shhexpressing cells. Mech Dev 75:107-115.

Lois C, Alvarez-Buylla A (1994) Long-distance neuronal migration in the adult mammalian brain. Science 264:1145-1148.

Lois C, Garcia-Verdugo JM, Alvarez-Buylla A (1996) Chain migration of neuronal precursors. Science 271:978-981.

Lu S, Shashikant CS, Ruddle FH (1996) Separate cis-acting elements determine the expression of mouse Dbx gene in multiple spatial domains of the central nervous system. Mech Dev 58:193-202.

Luskin MB (1993) Restricted proliferation and migration of postnatally generated neurons derived from the forebrain subventricular zone. Neuron 11:173-189.

Marin O, Rubenstein JL (2001) A long, remarkable journey: tangential migration in the telencephalon. Nat Rev Neurosci 2:780-790.

Marin O, Yaron A, Bagri A, Tessier-Lavigne M, Rubenstein JL (2001) Sorting of striatal and cortical interneurons regulated by semaphorinneuropilin interactions. Science 293:872-875.

Marin O, Plump AS, Flames N, Sanchez-Camacho C, Tessier-Lavigne M, Rubenstein JL (2003) Directional guidance of interneuron migration to the cerebral cortex relies on subcortical Slit1/2-independent repulsion and cortical attraction. Development 130:1889-1901.

Markram H, Toledo-Rodriguez M, Wang Y, Gupta A, Silberberg G, Wu C (2004) Interneurons of the neocortical inhibitory system. Nat Rev Neurosci 5:793-807.

Marshall CA, Goldman JE (2002) Subpallial dlx2-expressing cells give rise to astrocytes and oligodendrocytes in the cerebral cortex and white matter. J Neurosci 22:9821-9830.

McConnell J, Angevine Jr JB (1983) Time of neuron origin in the amygdaloid complex of the mouse. Brain Res 272:150-156.

Medina L, Legaz I, Gonzalez G, De Castro F, Rubenstein JL, Puelles L (2004) Expression of Dbx1, Neurogenin 2, Semaphorin 5A, Cadherin 8, and Emxl distinguish ventral and lateral pallial histogenetic divisions in the developing mouse claustroamygdaloid complex. J Comp Neurol 474:504-523.

Misson JP, Edwards MA, Yamamoto M, Caviness Jr VS (1988) Identification of radial glial cells within the developing murine central nervous system: studies based upon a new immunohistochemical marker. Brain Res Dev Brain Res 44:95-108.

Molnár Z, Butler AB (2002) The corticostriatal junction: a crucial region for forebrain development and evolution. BioEssays 24:530-541.

Monuki ES, Walsh CA (2001) Mechanisms of cerebral cortical patterning in mice and humans. Nat Neurosci [Suppl] 4:1199-1206.

Nery S, Fishell G, Corbin JG (2002) The caudal ganglionic eminence is a source of distinct cortical and subcortical cell populations. Nat Neurosci 5:1279-1287.

Nery S, Corbin JG, Fishell G (2003) Dlx2 progenitor migration in wild type and Nkx2.1 mutant telencephalon. Cereb Cortex 13:895-903.

Okabe M, Ikawa M, Kominami K, Nakanishi T, Nishimune Y (1997) "Green mice" as a source of ubiquitous green cells. FEBS Lett 407:313-319.

Paxinos G, Franklin KBJ (2000) The mouse brain in stereotaxic coordinates, Ed 2. San Diego: Academic.

Price JL, Russchen FT, Amaral DG (1987) Integrated systems of the CNS. In: Handbook of clinical neuroanatomy, Pt I (Björkland A, Hökfelt T, Swanson LW, eds), pp 279-387. San Diego: Elsevier Science.

Puelles L, Rubenstein JL (2003) Forebrain gene expression domains and the evolving prosomeric model. Trends Neurosci 26:469-476.

Puelles L, Kuwana E, Puelles E, Rubenstein JL (1999) Comparison of the mammalian and avian telencephalon from the perspective of gene expression data. Eur J Morphol 37:139-150.

Puelles L, Kuwana E, Puelles E, Bulfone A, Shimamura K, Keleher J, Smiga S, Rubenstein JL (2000) Pallial and subpallial derivatives in the embryonic chick and mouse telencephalon, traced by the expression of the genes Dlx-2, Emx-1, Nkx-2.1, Pax-6, and Tbr-1. J Comp Neurol 424:409-438.

Rakic $P$ (1974) Neurons in rhesus monkey visual cortex: systematic relation between time of origin and eventual disposition. Science 183:425-427.

Rallu M, Corbin JG, Fishell G (2002) Parsing the prosencephalon. Nat Rev Neurosci 3:943-951.

Remedios R, Subramanian L, Tole S (2004) LIM genes parcellate the embryonic amygdala and regulate its development. J Neurosci 24:6986-6990.

Smart IHM, Sturrock RR (1979) Ontogeny of the neostriatum. In: The neostriatum (Divac I, Öberg RGE, eds). Oxford: Pergamon.

Stenman J, Toresson H, Campbell K (2003a) Identification of two distinct progenitor populations in the lateral ganglionic eminence: implications for striatal and olfactory bulb neurogenesis. J Neurosci 23:167-174.

Stenman J, Yu RT, Evans RM, Campbell K (2003b) Tlx and Pax6 co-operate genetically to establish the pallio-subpallial boundary in the embryonic mouse telencephalon. Development 130:1113-1122.

Stenman JM, Wang B, Campbell K (2003c) Tlx controls proliferation and patterning of lateral telencephalic progenitor domains. J Neurosci 23:10568-10576.

Stoykova A, Fritsch R, Walther C, Gruss P (1996) Forebrain patterning defects in Small eye mutant mice. Development 122:3453-3465.

Stoykova A, Treichel D, Hallonet M, Gruss P (2000) Pax6 modulates the dorsoventral patterning of the mammalian telencephalon. J Neurosci 20:8042-8050.

Sussel L, Marin O, Kimura S, Rubenstein JL (1999) Loss of Nkx2.1 homeobox gene function results in a ventral to dorsal molecular respecification within the basal telencephalon: evidence for a transformation of the pallidum into the striatum. Development 126:3359-3370.

Suzuki SO, Goldman JE (2003) Multiple cell populations in the early post- 
natal subventricular zone take distinct migratory pathways: a dynamic study of glial and neuronal progenitor migration. J Neurosci 23:4240-4250.

Swanson LW, Petrovich GD (1998) What is the amygdala? Trends Neurosci 21:323-331.

Szucsik JC, Witte DP, Li H, Pixley SK, Small KM, Potter SS (1997) Altered forebrain and hindbrain development in mice mutant for the Gsh-2 homeobox gene. Dev Biol 191:230-242.

Tamamaki N, Nakamura K, Kaneko T (2001) Cell migration from the corticostriatal angle to the basal telencephalon in rat embryos. NeuroReport 12:775-780.

Tole S, Remedios R, Saha B, Stoykova A (2005) Selective requirement of Pax6, but not Emx2, in the specification and development of several nuclei of the amygdaloid complex. J Neurosci 25:2753-2760.

Tomioka N, Osumi N, Sato Y, Inoue T, Nakamura S, Fujisawa H, Hirata T (2000) Neocortical origin and tangential migration of guidepost neurons in the lateral olfactory tract. J Neurosci 20:5802-5812.

Toresson H, Campbell K (2001) A role for Gsh1 in the developing striatum and olfactory bulb of Gsh2 mutant mice. Development 128:4769-4780.

Toresson H, Potter SS, Campbell K (2000) Genetic control of dorsal-ventral identity in the telencephalon: opposing roles for Pax6 and Gsh2. Development 127:4361-4371.

Waclaw RR, Allen II ZJ, Bell SM, Erdelyi F, Szabo G, Potter SS, Campbell K
(2006) The zinc finger transcription factor Sp8 regulates the generation and diversity of olfactory bulb interneurons. Neuron 49:503-516.

Wichterle H, Garcia-Verdugo JM, Alvarez-Buylla A (1997) Direct evidence for homotypic, glia-independent neuronal migration. Neuron 18:779-791.

Wichterle H, Garcia-Verdugo JM, Herrera DG, Alvarez-Buylla A (1999) Young neurons from medial ganglionic eminence disperse in adult and embryonic brain. Nat Neurosci 2:461-466.

Wichterle H, Turnbull DH, Nery S, Fishell G, Alvarez-Buylla A (2001) In utero fate mapping reveals distinct migratory pathways and fates of neurons born in the mammalian basal forebrain. Development 128:3759-3771.

Xu Q, Cobos I, De La Cruz E, Rubenstein JL, Anderson SA (2004) Origins of cortical interneuron subtypes. J Neurosci 24:2612-2622.

Yoon K, Nery S, Rutlin ML, Radtke F, Fishell G, Gaiano N (2004) Fibroblast growth factor receptor signaling promotes radial glial identity and interacts with Notch1 signaling in telencephalic progenitors. J Neurosci 24:9497-9506.

Yun K, Potter S, Rubenstein JL (2001) Gsh2 and Pax6 play complementary roles in dorsoventral patterning of the mammalian telencephalon. Development 128:193-205.

Zirlinger M, Kreiman G, Anderson DJ (2001) Amygdala-enriched genes identified by microarray technology are restricted to specific amygdaloid subnuclei. Proc Natl Acad Sci USA 98:5270-5275. 